\title{
CHLORHEXIDINE-RELEASING IMPLANT COATING ON INTRAMEDULLARY NAIL REDUCES INFECTION IN A RAT MODEL
}

\author{
S.M. Shiels ${ }^{1, *}$, M. Bouchard ${ }^{2}$, H. Wang ${ }^{2}$ and J.C. Wenke ${ }^{1}$ \\ ${ }^{1}$ United States Army Institute of Surgical Research, Extremity Trauma and Regenerative Medicine \\ Task Area, Joint Base San Antonio-Fort Sam, Houston, Texas, USA \\ ${ }^{2}$ Teleflex Inc., Cambridge, Massachusetts, USA
}

\begin{abstract}
The use of internal intramedullary nails for long bone fracture fixation is a common practice among surgeons. Bacteria naturally attach to these devices, increasing the risk for wound infection, which can result in non- or malunion, additional surgical procedures and extended hospital stays. Intramedullary nail surface properties can be modified to reduce bacterial colonisation and potentially infectious complications. In the current study, a coating combining a non-fouling property with leaching chlorhexidine for orthopaedic implantation was tested. Coating stability and chlorhexidine release were evaluated in vitro. Using a rat model of intramedullary fixation and infection, the effect of the coating on microbial colonisation and fracture healing was evaluated in vivo by quantitative microbiology, micro-computed tomography, plain radiography, three-point bending and/or histology. Low dose systemic cefazolin was administered to increase the similarities to clinical practice, without overshadowing the effect of the anti-infective coating. When introduced into a contaminated wound, the non-fouling chlorhexidine-coated implant reduced the overall bacteria colonisation within the bone and on the implant, reduced the osteolysis and increased the radiographic union, confirming its potential for reducing complications in wounds at high risk of infection. However, when implanted into a sterile wound, non-union increased. Further studies are required to best optimise the anti-microbial effectiveness, while not sacrificing fracture union.
\end{abstract}

Keywords: Surface modification, non-fouling coating, orthopaedic fixation, osteomyelitis, Staphylococcus aureus.

* Address for correspondence: Stefanie M. Shiels, PhD, 3698 Chambers Pass, Bldg 3611, JBSA-Fort Sam Houston, TX 78234, USA.

Telephone: +1 2105393654 Email: stefanie.m.shiels.ctr@mail.mil

Copyright policy: This article is distributed in accordance with Creative Commons Attribution Licence (http://creativecommons.org/licenses/by-sa/4.0/).

\section{Introduction}

Fractures to the extremities from high energy trauma require fixation hardware to stabilise the injury, traditionally an internal intramedullary (IM) nail or an external ring fixator. Despite extensive measures including multiple rounds of antibiotics, aggressive debridement and delayed definitive treatment, the rate of infection for Gustilo-Anderson Type III fractures can increase to almost $52 \%$ (Gustilo and Anderson 1976; Gustilo et al., 1984; Patzakis and Wilkins 1989; Harris et al., 2009). The compromised local immunity and implanted fixation devices encourage bacterial colonisation and formation of biofilms that are difficult to eradicate (Gristina et al., 1988; Costerton et al., 2005). Reduced interaction between the implant and contaminated fracture can be achieved by using an external fixation device (Keeling et al., 2008). However, external fixators are difficult to place, expensive, cumbersome to the wearer and characterised by higher rates of malunion (O'Toole et al., 2017). Instead, internal fixation devices, such as IM nails, have many benefits over external fixation. IM nails are easy to place and relatively inexpensive, have high rates of successful unions and provide a better quality of life (Hofmann $e t$ al., 2015); however, the incorporation of IM nails into highly contaminated wounds results in high rates of infection (Lerner et al., 2006; Keeling et al., 2008). To minimise this risk, bacterial adhesion and biofilm colonisation must be reduced, thus decreasing the onset of infection initiated from the implant surface.

Recent strategies to reduce implant-associated infection revolve around the use of antimicrobial- 
coated fixation hardware devices (Schmidmaier et al., 2006). In a rat model, Lucke et al. $(2003,2005)$ show that a gentamicin-coated IM nail reduces bacterial contamination, while not interfering with natural bone healing. The same IM nail shows promising infection prevention in a human case series and it is approved for use outside the United States (Fuchs et al., 2011; Metsemakers et al., 2015). With a rise in antimicrobial resistance, research has been driven towards alternate antifouling techniques and bactericidal compounds. Chlorhexidine (CHX) is used as an implant coating for catheters and is recommended as a topical antibacterial agent for surgical site preparation (Maki et al., 1997; Lim and Kam 2008; Bebko et al., 2015). At high concentrations, CHX is a broad-spectrum antiseptic with known activity against Staphylococcus aureus (S. aureus), the primary pathogen of orthopaedic infections (Hugo and Longworth 1964; McDonnell and Russell 1999; Zimmerli and Sendi, 2017). However, CHX is a cytotoxic compound (Pucher and Daniel, 1992) to be used with caution on implants near healing tissues. Preliminary studies on a titanium implant confirm that the use of a $\mathrm{CHX}$ coating decreases bacterial colonisation, despite its effect upon bone healing not having been confirmed (Darouiche et al., 1998; Riool et al., 2017). On the other hand, the addition of an antifouling surface modification can prevent the initial bacterial attachment and biofilm formation (Campoccia et al., 2013). Zwitterionic compounds, such as poly-sulphobetaines, are highly resistant to non-specific proteins and reduce surface biofilm formation (Cheng et al., 2007; Smith et al., 2012). Smith et al. (2012) and Gupta et al. (2014) apply poly-sulphobetaines to vascular catheters to reduce microbial attachment, thus reducing thrombus formation and demonstrating chemical translation to titanium surfaces for potential orthopaedic use. However, their utility in reducing biofilm formation on orthopaedic devices in vivo is not thoroughly investigated (Sin et al., 2014; Wang et al., 2014).

The goal of this project was to determine the effectiveness of a non-fouling, CHX-releasing surface modification in reducing the incidence of $S$. aureus bone infection, while evaluating the effect of the coating on natural, spontaneous fracture healing in a rat model.

\section{Materials and Methods}

\section{Modified Kirschner wire preparation and CHX release}

Titanium Kirschner wires (K-wires, $1.25 \mathrm{~mm}$, partially threaded; MK Medical GmbH \& Co., Stahlhofen, Germany) were modified with the deposition of a proprietary polymer layer, with or without leaching $\mathrm{CHX}$, followed by brush polybetaine grafting, with a final thickness of $27.0 \mu \mathrm{m}$ (Teleflex Inc., Cambridge, MA, USA) (Smith et al., 2012; Weinstock et al., 2012; Wang et al., 2014) (Fig. 1). Briefly, K-wires were coated using a dip-coating technique to apply a non-porous polymer reservoir containing either CHX diacetate or polymer alone. Then, the coated $\mathrm{K}$-wires were introduced into a polymerisation initiator followed by immersion at $37{ }^{\circ} \mathrm{C}$ for $16 \mathrm{~h}$ into a solution of $10 \% \mathrm{~N}$-(3-Sulphopropyl)-Nmethacryloxyethyl-N,N-dimethylammonium betaine (SBMA) containing $5 \mathrm{mM}$ ferrous (II) gluconate. The coated K-wires, SBMA or SBMA + CHX, were washed at room temperature in $0.9 \% \mathrm{NaCl}$ followed by deionised water, air dried, sterilised with ethylene oxide and stored until use. A $20 \%$ CHX weight loss was measured from the polymer layer during the final polymerisation, with a final $\mathrm{CHX}$ loading of $23 \mu \mathrm{g} / \mathrm{mm}^{2}$ titanium surface, which was determined by calculating dry wire weight change after coating. To evaluate the CHX release from the surface modification, $100 \mathrm{~mm}$ SBMA + CHX-coated $\mathrm{K}$-wires were placed in $50 \mathrm{~mL}$ phosphate buffered saline (PBS) at $37^{\circ} \mathrm{C}$. At specific time points, $\mathrm{CHX}$ concentration was measured by spectroscopy (Synergy 2, BioTek, Winooski, VT, USA) at $231 \mathrm{~nm}$ ( $n=4$, 3 measurements per sample). The stability of the SBMA brush layer was evaluated by incubating coated titanium in bovine serum albumin for $30 \mathrm{~d}$ at $37^{\circ} \mathrm{C}$ and measuring SBMA thickness by attenuated total reflectance infrared spectroscopy (Weinstock et al., 2012).

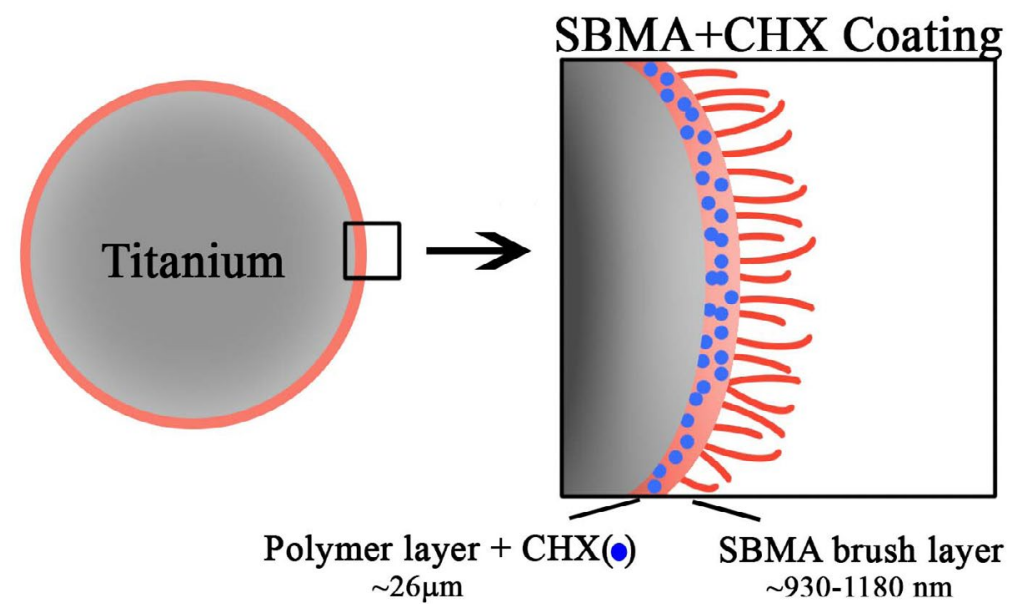

Fig. 1. Schematic of the coating morphology. A thin polymer layer, with or without CHX, was applied to the titanium surface. Next, the non-fouling SBMA brush layer $(\sim 930-1180 \mathrm{~nm})$ was bonded to the polymer layer for a final modification thickness of $27 \mu \mathrm{m}$ (figure not to scale). 
Table 1. Experimental design of in vivo studies. Each experiment was delineated by the presence $(+)$ or absence (-) of $10^{2} \mathrm{CFU}$ of bacteria and/or a $1 \mathrm{~mm}$ osteotomy through the midshaft. Experiment 3 and 4 also investigated the addition of systemic cefazolin $(0,0.5$ and $1.0 \mathrm{mg} / \mathrm{kg})$ given twice daily for $72 \mathrm{~h}$. Group $(n)$ indicates the number of animals within each group that received surgery. Outcome $(n)$ indicate the number of animals that were assessed with the identified measurement tool. Unmodified indicates an unmodified titanium K-wire; SBMA, SBMA and polymer-reservoir-only-coated K-wire; SBMA + CHX, SBMA and polymer reservoir with releasing $\mathrm{CHX}$-coated $\mathrm{K}$-wire. $1^{\circ}$ and $2^{\circ}$ indicate primary and secondary outcome measurement tools, respectively. Data from experiment 1 were used to perform a power analysis for experiment 3 , to reduce the number of animals necessary to obtain meaningful data.

\begin{tabular}{|c|c|c|c|c|}
\hline Experiment & Osteotomy & Inoculation ( $\left.10^{2} \mathrm{CFU}\right)$ & Groups (n) & Outcome $(n)$ \\
\hline 1 & 每 & 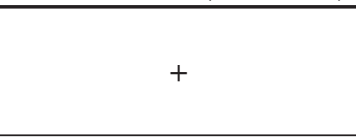 & $\begin{array}{l}\text { Unmodified (16) } \\
\text { SBMA (16) } \\
\text { SBMA + CHX (16) }\end{array}$ & $\begin{array}{c}\text { Infection } \\
1^{\circ} \text { Bacteria enumeration (all) }\end{array}$ \\
\hline 2 & + & - & $\begin{array}{l}\text { Unmodified (20) } \\
\text { SBMA (19) } \\
\text { SBMA + CHX (20) }\end{array}$ & $\begin{array}{l}\text { Bone Healing } \\
1^{\circ} \mu \mathrm{CT} \text { and plain radiology (all) } \\
2^{\circ} \text { Histology (7); mechanical (13) } \\
2^{\circ} \text { Histology (4); mechanical (14) } \\
2^{\circ} \text { Histology (7); mechanical (13) }\end{array}$ \\
\hline 3 & + & + & $\begin{array}{c}0 \mathrm{mg} / \mathrm{kg} \text { cefazolin } \\
\text { Unmodified (5) } \\
\text { SBMA + CHX (5) } \\
0.5 \mathrm{mg} / \mathrm{kg} \text { cefazolin } \\
\text { Unmodified (5) } \\
\text { SBMA + CHX (5) } \\
1 \mathrm{mg} / \mathrm{kg} \text { cefazolin } \\
\text { Unmodified (5) } \\
\text { SBMA + CHX (5) }\end{array}$ & $\begin{array}{c}\text { Infection } \\
1^{\circ} \text { Bacteria enumeration (all) } \\
2^{\circ} \text { Plain radiology (all) }\end{array}$ \\
\hline 4 & + & + & $\begin{array}{l}1.0 \mathrm{mg} / \mathrm{kg} \text { cefazolin } \\
\text { Unmodified (12) } \\
\text { SBMA+CHX (12) }\end{array}$ & $\begin{array}{c}\text { Bone Healing } \\
1^{\circ} \text { Mechanical (all) } \\
2^{\circ} \mu \mathrm{CT} \text { and plain radiology (all) } \\
2^{\circ} \text { Histology (5) } \\
2^{\circ} \text { Histology (7) }\end{array}$ \\
\hline
\end{tabular}

\section{CHX susceptibility testing}

The minimum inhibitory concentration (MIC) of $\mathrm{CHX}$ diacetate was determined using the Clinical and Laboratory Standards Institute broth dilution method (CLSI, 2013). A methicillin-susceptible S. aureus (UAMS-1, 49230, ATCC), isolated from a patient with chronic osteomyelitis, was cultured in trypsin soy broth (TSB) to a final concentration of $10^{6}$ colony forming unit (CFU)/mL (Gillaspy et al., 1995). In a 96-well plate, $90 \mu \mathrm{L}$ of UAMS-1 were added to serial dilutions of $\mathrm{CHX}(0.125-8 \mu \mathrm{g} / \mathrm{mL})$. Media control (no bacteria) and positive control (no $\mathrm{CHX}$ ) wells were included. Plates were incubated at $37^{\circ} \mathrm{C}$ for $20 \mathrm{~h}$. MIC was determined as the first concentration of $\mathrm{CHX}$ with visibly reduced medium turbidity as compared to the positive control.

\section{Statistical analysis}

Release kinetics are presented as mean \pm standard deviation (SD). Bacteria enumeration data were logtransformed prior to statistical analysis by one-way or two-way analysis of variance (ANOVA), followed by Tukey's post-hoc test. Quantitative micro-computed tomography $(\mu \mathrm{CT})$ is presented as means \pm standard error of the mean (SEM) and was analysed by oneway ANOVA. Categorical data, such as the presence of signs of infection or union versus non-union, were analysed by Fisher's $2 \times 2$ contingency table. Significance for all tests was set to $p<0.05$.

\section{In vivo - K-wire implant procedure}

All animal procedures were approved by the Institutional Animal Care and Use Committee of the US Army Institute of Surgical Research and were conducted in compliance with the Animal Welfare Act, the implementing Animal Welfare Regulations and the principles of the Guide for the Care and Use of Laboratory Animals. A rat tibial IM nail model was used to evaluate the coated implant in 4 experiments. Briefly, Sprague-Dawley rats (Harlan Laboratories, Houston, TX, USA) were premedicated with sustained-release buprenorphine approximately 30 min prior to anaesthetic induction with 1-3\% isoflurane in oxygen. The right hindlimb was shaved, disinfected with alcohol and betadine and draped for sterile surgery. An incision was made over the knee 
Table 2. Histological scoring system for experiment 4.

\begin{tabular}{|l|}
\hline Tissue scoring \\
\hline Callus quality \\
\hline $0=$ Boney union \\
1 = Most of callus was new bone \\
2 = Callus was composed of new bone and spindle cells - majority were spindle cells \\
3 = Callus was composed of spindle cells and inflammatory cells - majority were spindle cells \\
$4=$ Callus was composed of spindle cells and inflammatory cells - most of callus was inflammatory cells \\
\hline Bacteriological scoring \\
\hline Bacterial presence within medullary canal, cortical bone or fracture callus \\
\hline $0=$ None observed \\
1 = Observed \\
\hline Bacterial location \\
\hline 1 = Bone surface \\
2 = Lacuna \\
3 = Both \\
\hline
\end{tabular}

and lower leg, through the anterior compartment, revealing the patella and tibialis anterior muscle. Blunt dissection was used to elevate the tibialis anterior muscle from the tibia and to expose the tibial plateau through the patellar tendon, with careful attention to maintain muscle and tendon attachments. An 18 gauge cannulated needle was used to create a hole through the tibial plateau and ream the medullary cavity of the tibia. The animals were separated into 4 experimental groups, receiving either an osteotomy, an inoculation of UAMS-1 or both (Table 1). The osteotomy was made using an ultrasonic dental tool, fitted with a serrated bone cutting insert (Piezosurgey Incorporated, Columbus, OH, USA) to minimise damage to surrounding tissues. Animals were further separated into treatment groups, receiving either an unmodified titanium control $\mathrm{K}$-wire, a SBMAcoated K-wire or an SBMA + CHX-coated K-wire. $\mathrm{K}$-wires were trimmed-flush to the tibial plateau to an average length of $26.77 \pm 0.28_{\text {SEM }} \mathrm{mm}$. Following the specific osteotomy or bacterial inoculation, the compartment and skin were closed with 4-0 vicryl and a plain radiograph was acquired using a closed cabinet X-ray (Ultrafocus100, Faxitron, Tucson, AZ, USA) to verify wire placement and, when applicable, osteotomy reduction. Animals recovered while having food and water available ad libitum. They were subjected to physical assessments twice daily for the first $3 \mathrm{~d}$ after surgery followed by weekly assessments thereafter to monitor for pain, stress and complications. In the presence of an abnormal gait, different from the other surgical mates, the animal was assessed radiographically. If rotation or crushing around the osteotomy were noted, the animals was sedated, euthanised and excluded from the study. At their designated time point, the animals were anaesthetised with isoflurane and euthanised with an overdose of a commercially available sodium pentobarbital (FatalPlus ${ }^{\circledR}$, Vortech Pharmaceuticals LTD, Dearborn, MI, USA). The limbs were recovered and processed depending on their outcome measure.
Experiment 1: effectiveness of the $\mathrm{CHX}$-releasing coating in reducing infection of intact bone

To determine the infection mitigation potential of the various IM wires in an intact bone, after reaming of the tibia, $10 \mu \mathrm{L}$ of $1.89 \times 10^{2} \pm 9.89_{\text {SEM }}$ CFU of UAMS-1 were delivered to the IM canal of SpragueDawley rats $(n=48)$ and incubated for 2 min prior to placement of the experimental K-wire (Table 1). The wires were threaded into the IM canal, twisted into the distal portion of the tibia and trimmed-flush within the tibial plateau. After 2 weeks, the animals were anaesthetised and euthanised, the hindlimb aseptically harvested and processed for bacterial enumeration.

Experiment 2: effect of the CHX-releasing coating on normal fracture healing

To determine the impact of the coating on normal bone healing in a sterile environment, following reaming of the tibia in Sprague-Dawley rats $(n=59)$, a complete $1 \mathrm{~mm}$ osteotomy was created through the tibia, approximately $12 \mathrm{~mm}$ distal to the tibial plateau. The wires were threaded into the IM canal and twisted into the distal portion of the tibia to stabilise the bone. After 4 weeks, the animals were euthanised, the hindlimb harvested and placed into phosphate buffered saline (PBS) or $10 \%$ neutral buffered formalin. All tibiae were analysed for bone formation by $\mu \mathrm{CT}$. Histology was performed on 7 (unmodified control and SBMA + CHX) and 4 (SBMA) tibiae from each group. Mechanical testing was performed on the remaining tibiae from each group not used for histology.

Experiment 3: contribution of systemic antibiotics to the effectiveness of the CHX-releasing coating in a contaminated fractured bone

The goal of this experiment was to determine the infection mitigation potential of the modified IM K-wire when used to stabilise a tibia following an osteotomy in Sprague-Dawley rats $(n=30)$. Following 
reaming of the tibia, a complete $1 \mathrm{~mm}$ osteotomy was created through the tibia, approximately $12 \mathrm{~mm}$ distal to the tibial plateau. $10 \mu \mathrm{L}$ of $5.9 \times 10^{2} \pm 30.8_{\text {SEM }} \mathrm{CFU}$ of UAMS-1 were applied to the IM canal and incubated for $2 \mathrm{~min}$ prior to placement of the experimental $\mathrm{K}$-wire. The wires, either unmodified or SBMA+CHX, were threaded into the IM canal and twisted into the distal portion of the tibia to stabilise the bone. The animals were separated into three systemic antibiotic groups (Table 1), each group receiving either $1.0 \mathrm{mg} /$ $\mathrm{kg}$ cefazolin, $0.5 \mathrm{mg} / \mathrm{kg}$ cefazolin or saline as a control. During the first $72 \mathrm{~h}$, the animals received twice daily injections of cefazolin or saline. After 2 weeks, the animals were anaesthetised and euthanised, the hindlimb aseptically harvested and processed for bacterial enumeration.

Experiment 4: overall usefulness of a CHX-releasing coating in a contaminated fracture healing model

To evaluate the overall utility of the CHX coating in a contaminated fracture model, infection prevention and functional healing were measured in SpragueDawley rats $(n=24)$. Following reaming of the tibia, a complete $1 \mathrm{~mm}$ osteotomy was created through the tibia, approximately $12 \mathrm{~mm}$ distal to the tibial plateau. $10 \mu \mathrm{L}$ of $5.58 \times 10^{2} \mathrm{CFU}$ of UAMS- 1 were applied to the IM canal and incubated for 2 min prior to placement of the experimental K-wire. The wires were threaded into the IM canal and twisted into the distal portion of the tibia to stabilise the bone. During the first $72 \mathrm{~h}$, the animals received twice daily sub-cutaneous injection of $1.0 \mathrm{mg} / \mathrm{kg}$ cefazolin, as this dose caused the highest reduction of bacteria within the wound when combined with the SBMA $+\mathrm{CHX}$-coated wire (experiment 3). After 4 weeks, the animals were anaesthetised and euthanised, the hindlimb harvested and placed in PBS or $10 \%$ neutral buffered formalin. Fracture healing and bacteria colonisation were evaluated using $\mu \mathrm{CT}$, histology and mechanical testing.

\section{Bacterial enumeration}

Upon aseptic harvesting of the right tibia, the bone was snap-frozen in liquid nitrogen, pulverised into a fine powder, resuspended in sterile saline and vortexed for $30 \mathrm{~s}$ (Belmatoug et al., 1996; Shiels et al., 2015). Wires were sonicated in saline solution for $15 \mathrm{~min}$. The supernatant from the bone homogenate and K-wire was serially diluted in sterile normal saline, plated onto sheep's blood agar (Thermo Fisher Scientific) and incubated overnight at $37^{\circ} \mathrm{C}$. Bacteria colonies were counted and normalised to tissue or wire mass.

\section{$\mu \mathrm{CT}$}

$\mu \mathrm{CT}$ was used to evaluate the total bone formation surrounding the healing osteotomy of each tibia. The tibiae were scanned following removal of the implanted K-wires using the VivaCT40 (Scanco Medical, Bassersdorf, Switzerland) at $70 \mathrm{kVp}$ and $114 \mu \mathrm{A}$. The scan resolution was $21 \mu \mathrm{m}$ with a $300 \mathrm{~ms}$ integration time. For experiment 2, the analysed region encompassed the entire fracture callus and was restricted to a total length of $6 \mathrm{~mm}$ ( $3 \mathrm{~mm}$ proximal and $3 \mathrm{~mm}$ distal to osteotomy). For experiment 4 , a distinct osteotomy location could not be defined due to intense osteolysis; therefore, a total diaphysial length of $9 \mathrm{~mm}$ (not necessarily centered on the osteotomy as in experiment 2) was evaluated.

\section{Mechanical evaluation}

Mechanical stability was measured by three-point bending (LS5, Lloyd Instruments, Largo, FL, USA). Wires and excess tissue were removed from the tibia. The tibiae were placed onto the support struts, medial side down and stressed until fracture. A $20 \mathrm{~mm}$ support span was used with a strain rate of $2 \mathrm{~mm} / \mathrm{min}$ and a preload of $0.1 \mathrm{~N}$. If the tibiae did not maintain integrity across the support span before or upon preload, bones were determined as not fused and stress-to-fracture was calculated as $0 \mathrm{~N}$. Tibiae were strained until a significant drop in stress was detected by the instrument, which then stopped.

\section{Histology}

The harvested tibiae were fixed in $10 \%$ neutral buffered formalin. The wires were removed and the bones were decalcified in $5 \%$ formic acid for $21 \mathrm{~d}$ and

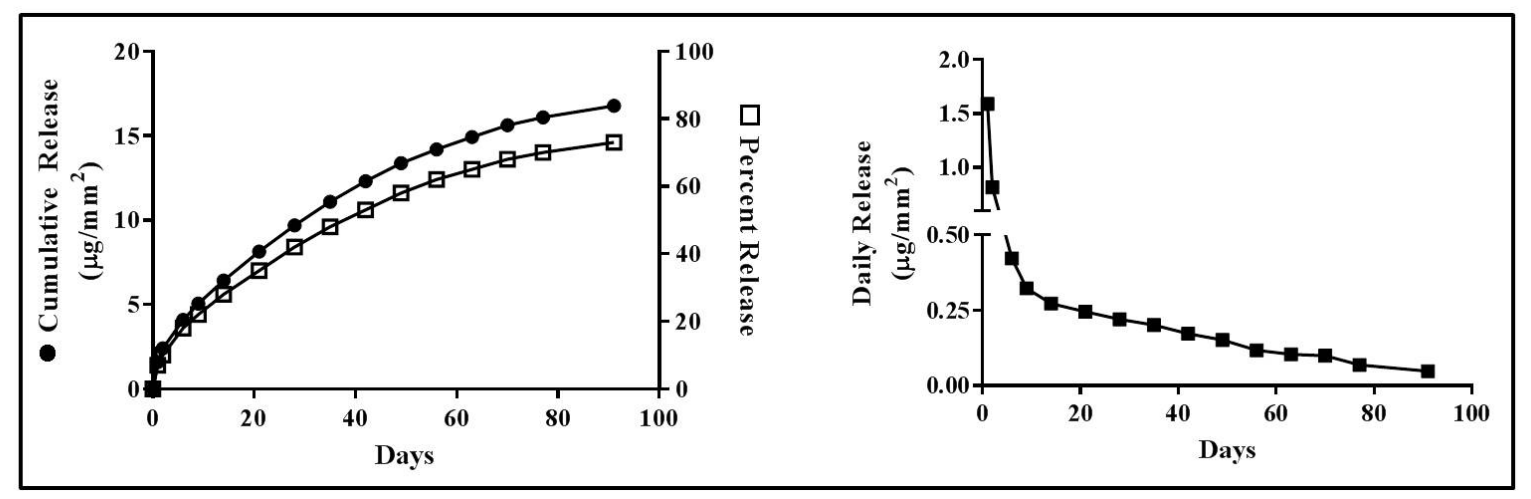

Fig. 2. Cumulative release of $\mathrm{CHX}$ from SBMA + CHX-modified titanium K-wires. Cumulative release of CHX after $91 \mathrm{~d}$ was $16.78 \mu \mathrm{g} / \mathrm{mm}^{2}$ (total 6,589.5 $\mu \mathrm{g}$ ), $78 \%$ of loaded CHX. With a total wire length of $100 \mathrm{~mm}$, there was a total daily release of $70.9 \mu \mathrm{g}$ CHX per day in vitro $\left(0.18 \mu \mathrm{g} / \mathrm{mm}^{2} / \mathrm{d}\right)$. The limit of detection was 1. Error bars were too small to be represented. 
processed for paraffin embedding. A microtome was used to cut $5 \mu \mathrm{m}$-thick sections, which were mounted and stained with haematoxylin and eosin (H\&E) or modified gram stain (Becerra et al., 2016). Histological sections were scored by a board certified veterinary pathologist according to a semi-quantitative grading system (Table 2).

\section{Results}

In vitro stability and $\mathrm{CHX}$ release

The SBMA coating and CHX release were stable and followed first-order release kinetics. There was no significant change in SBMA thickness, from $1180 \pm 464 \mathrm{~nm}$ to $932 \pm 146 \mathrm{~nm}$, after $30 \mathrm{~d}$ of incubation $(p<0.05)$. CHX had a burst release followed by a steady diminishing release over a period of $90 \mathrm{~d}$, with a total $\mathrm{CHX}$ release of $16.78 \pm 0.038_{\mathrm{SD}} \mu \mathrm{g} / \mathrm{mm}^{2}$ (78\% of the loaded $\mathrm{CHX}$ ) and an average daily rate of $0.18 \mu \mathrm{g} / \mathrm{mm}^{2}$ (Fig. 2a,b). With an average wire length of $26.77 \pm 0.28_{\text {SEM }} \mathrm{mm}$, each animal was implanted with an average of $2.40 \mathrm{mg}$ CHX with an average total release of $18.9 \mu \mathrm{g} / \mathrm{d}$.

\section{CHX susceptibility}

CHX had a MIC of $2 \mu \mathrm{g} / \mathrm{mL}$ against UAMS-1.

\section{In vivo evaluation}

Experiment 1: the presence of $\mathrm{CHX}$ reduced infection in vivo

Compared to the unmodified control, the SBMAcoated wire did not reduce the number of bacteria either in the bone or on the wire; however, when $\mathrm{CHX}$ was added to the coating, there was an average $3 \mathrm{log}$ reduction of bacteria in the bone and $5.5 \mathrm{log}$ reduction of bacteria on the modified K-wire (Fig. 3a,b). 3 animals, 2 unmodified control and 1 SBMA, were euthanised and excluded due to uncontrollable oedema in the ipsilateral foot prior to study end.

Experiment 2: released $\mathrm{CHX}$ affected natural bone healing $\mathrm{CHX}$ within the surface modification affected bone formation and healing of a non-critical osteotomy, predominantly decreasing union rate. The total amount of bone formed around the osteotomy and measured by $\mu \mathrm{CT}$ was not altered by the inclusion of the SMBA or SBMA + CHX modification, compared to the unmodified control. Instead, in the medullary a

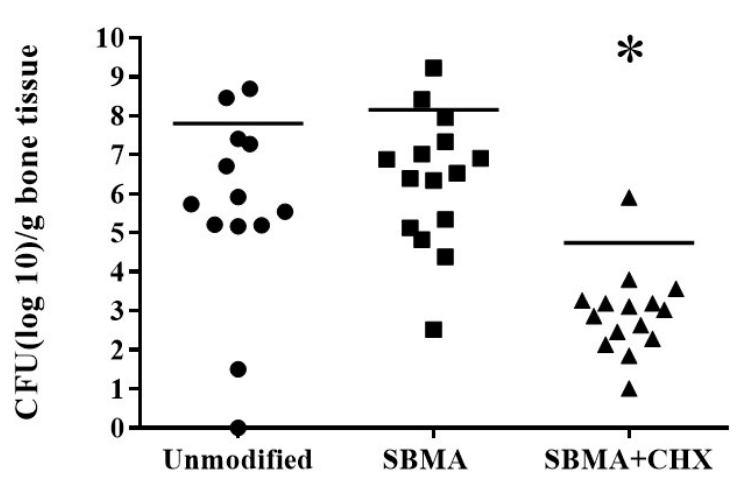

b

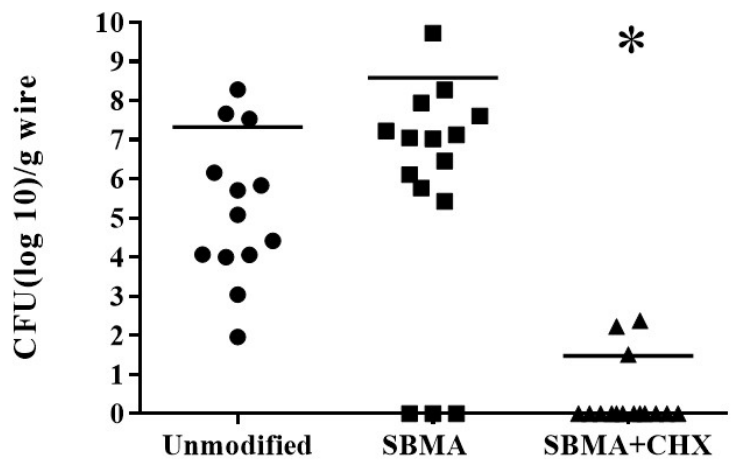

Fig. 3. Experiment 1. Bacteria recovered from (a) bone and (b) implanted K-wire. SBMA + CHX reduced the overall bacterial number in bone as compared to the unmodified control wire and the SBMA-onlycoated wire ${ }^{*} p<0.01$ one-way ANOVA of log-transformed data). SBMA + CHX reduced bacteria on the wire itself when compared to the unmodified control wire and the SBMA-only-coated wire $\left({ }^{*} p<0.01\right.$, ANOVA of log-transformed data).

a

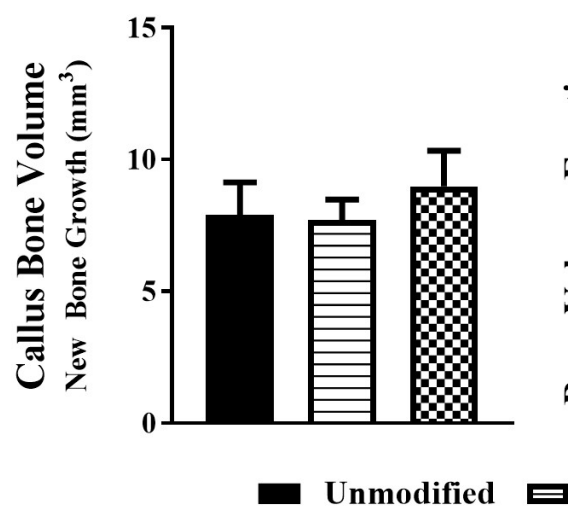

b

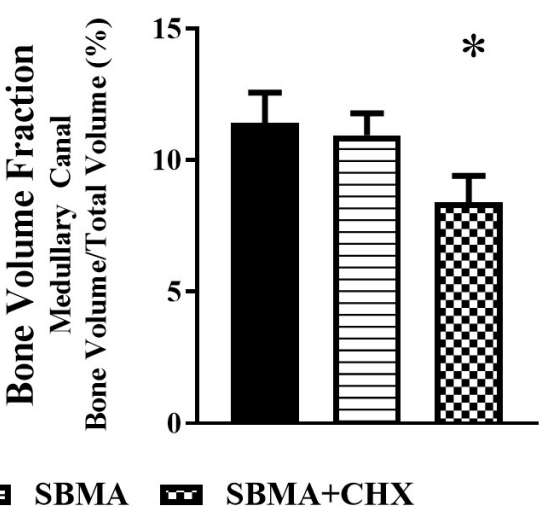

Fig. 4. Experiment 2. Bone volume of callus and fraction of the medullary canal as determined by $\mu \mathrm{CT}$. Callus bone volume was determined by drawing a region of interest (ROI) around the newly callused fracture line, spanning $3 \mathrm{~mm}$ distal and proximal from the osteotomy. Bone volume fraction was determined by drawing a ROI with the inner cortex as an outer border surrounding the fracture line, spanning $3 \mathrm{~mm}$ distal and proximal. The amount of bone was normalised to the total area measured. 
canal, the SBMA + CHX modification associated with a non-significant bone reduction (Fig. 4). Plain radiographs revealed similar bone and callus morphology around the osteotomy; however, longitudinal images from $\mu \mathrm{CT}$ suggested that the SBMA and SBMA + CHX coatings prevented the interaction between the host tissue and the implanted K-wire, indicated by a lack of tissue apposition to the area occupied by the removed implant (Fig. 5). Histology confirmed little difference among the groups in the types of tissues present in the fracture callus (Fig. 6). When evaluated for union at 4 weeks post-implantation, 10 of 13 animals presented bone unions in the unmodified control group as compared to 8 of $14(p=0.42)$ and 4 of $13(p<0.05)$ in the SBMA and SBMA + CHX groups, respectively. No difference was measured in the bending max load among experimental groups $(p=0.47)$, with max forces of $20.99 \pm 7.52 \mathrm{~N}, 12.85 \pm 5.66 \mathrm{~N}$ and $10.31 \pm 5.51 \mathrm{~N}$ in the unmodified control, SBMA and SBMA + CHX groups, respectively; whereas the contralateral limbs withstood an average bending max force of $86.84 \pm 2.27 \mathrm{~N}$. One animal (SBMA) was euthanised and excluded due to post-operative torsional destabilisation of the tibia.

Experiment 3: addition of systemic cefazolin increased treatment effect of SBMA $+\mathrm{CHX}$

When combined with an osteotomy, the ability of the SBMA + CHX modification for reducing bacterial bioburden decreased (Fig. 7). To boost similarities between clinical practices and potentially improve the effectiveness of the SBMA + CHX modification, systemic cefazolin, a standard antibiotic used in orthopaedic surgery, was administered by subcutaneous injection twice daily for $72 \mathrm{~h}$ following surgery. When 0.5 or $1.0 \mathrm{mg}$ cefazolin $/ \mathrm{kg}$ body weight were used, the bacterial bioburden within the bone and on the SBMA + CHX K-wire was significantly reduced $(p<0.05)$. The combined use of the SBMA + CHX K-wire and systemic cefazolin prevented the morphological changes observed in the unmodified control K-wires, as seen by X-ray (Fig. 8).

Experiment 4: SBMA + CHX-modified implants improved fracture healing in a contaminated model as compared to unmodified titanium

When a SMBA + CHX K-wire, combined with systemic cefazolin, was used to stabilise a contaminated osteotomy, an evident mitigation of osteolysis and increased radiographic union were measured as compared to the unmodified control wire (Table 3). In addition, although not statistically significant, bending max load increased from $4.3 \pm 4.3$ to $17.9 \pm 6.1 \mathrm{~N}(p=0.0998)$, but remained significantly lower than the non-fractured contralateral tibia $(84.4 \pm 1.6 \mathrm{~N}, p<0.0001)$. Due to osteolysis and thinning of cortical walls within the unmodified control group, quantitative $\mu \mathrm{CT}$ could not be accurately performed around the osteotomy and compared to the SBMA
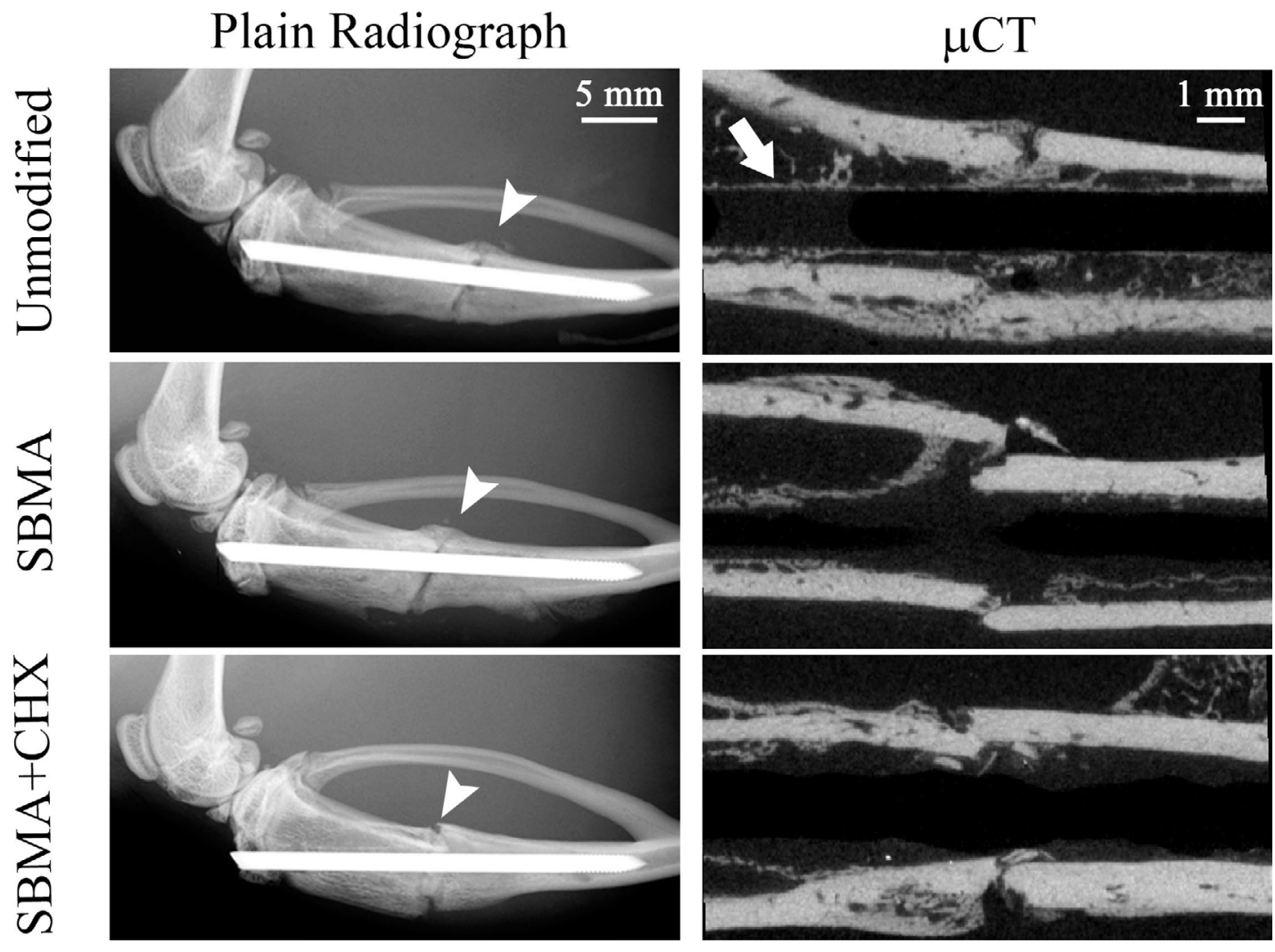

Fig. 5. Experiment 2. Radiographs 4 weeks post-operative. Plain radiographs showed intramedullary wire in place with signs of bony callus and fusion (arrowhead). Longitudinal $\mu \mathrm{CT}$ image through the tibia showed evidence of bone formation. Compared to the coated wires, the unmodified control group presented bone formation at the wire interface (arrow). 
+ CHX group. When comparing the morphology of the tibial diaphysis $(9 \mathrm{~mm})$, the total tissue volume of the tibia with the unmodified control wire was significantly larger than in the SBMA + CHX group, indicating an expansion of the tibial area (Fig. 9a). While this could indicate more callus formation, it was believed to be a periosteal reaction due to the bacteria because, although not statistically significant, bone volume fraction in the unmodified control appeared to decrease as compared to the SBMA + CHX group (Fig. 9b), which was corroborated by cross-sectional images (Fig. 9c). Morphological differences were observed in bone tissue when the unmodified control wire was used in place of the SBMA + CHX modified K-wire (Fig. 10). Whereas the tibiae with the modified $\mathrm{K}$-wire showed signs of bone formation in the form of a callus around the osteotomy site, the tibiae with the unmodified control K-wire exhibited signs of active a
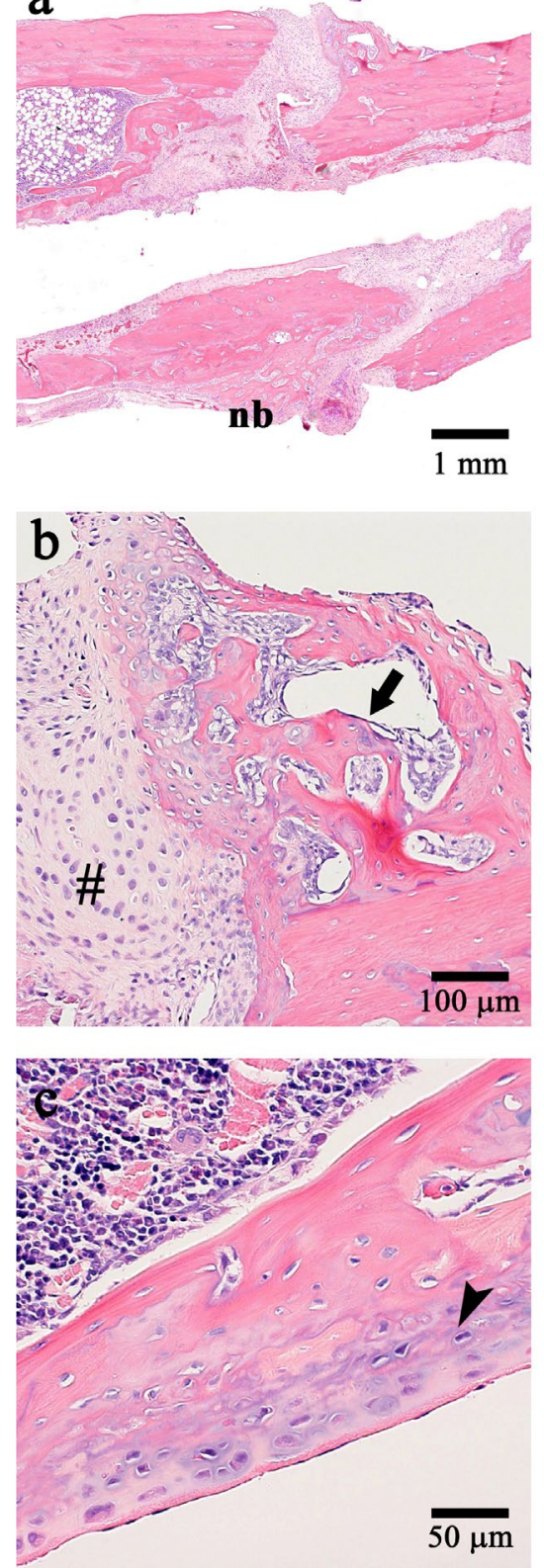
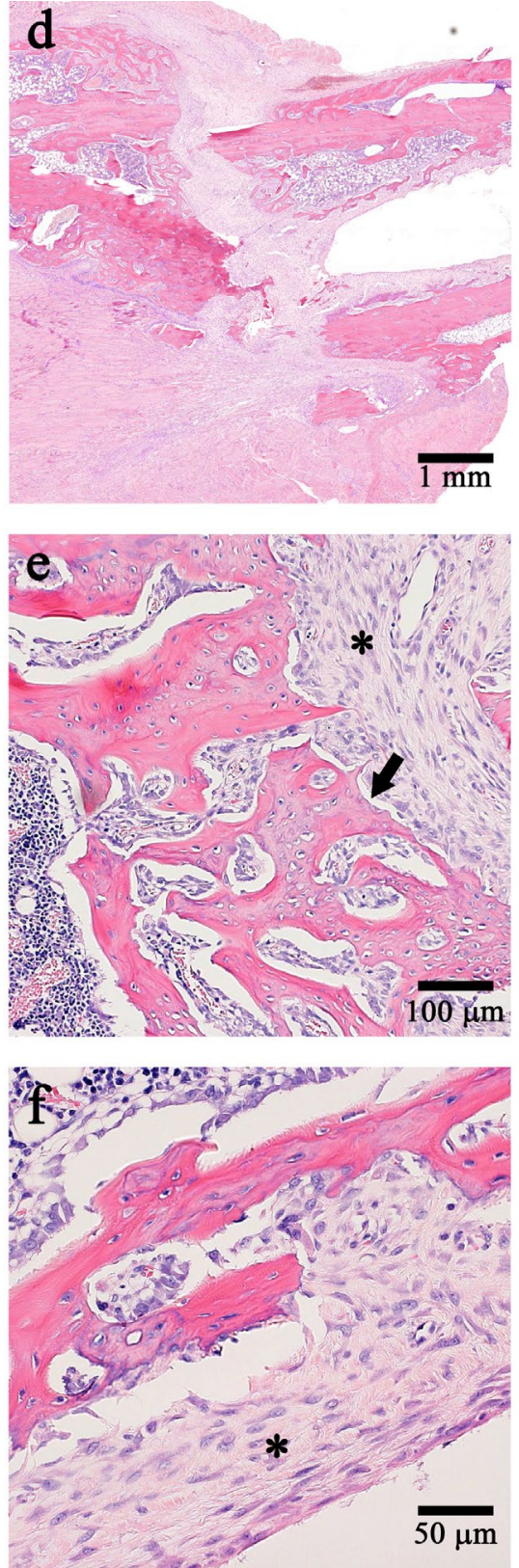
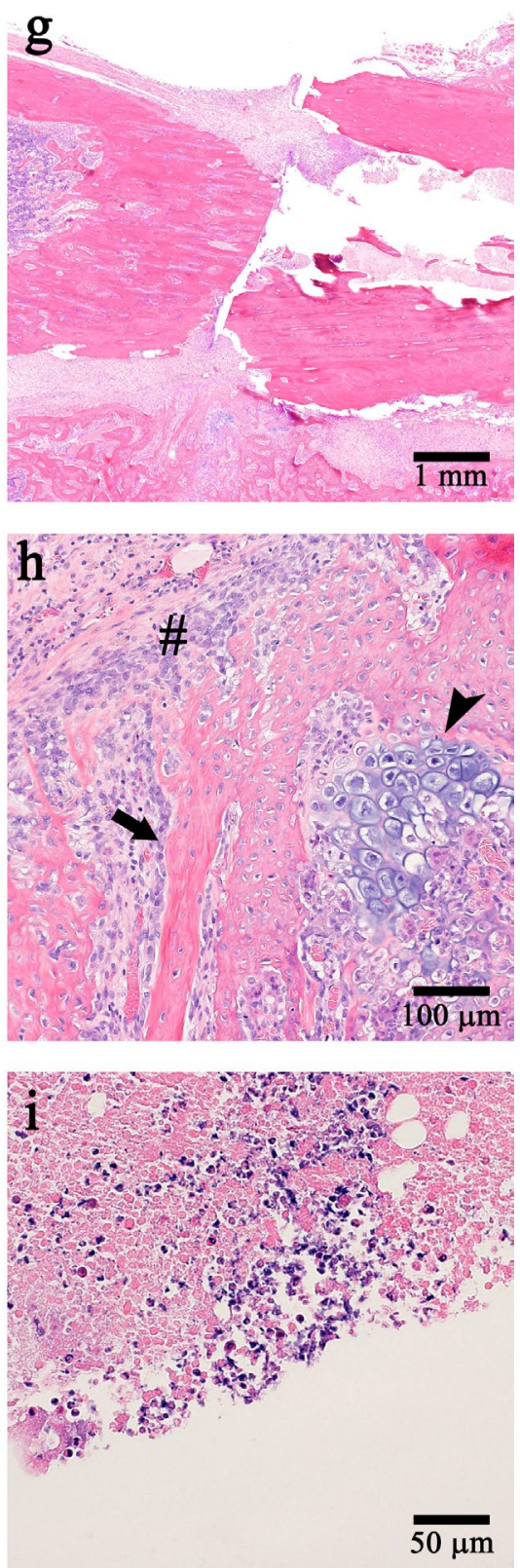

Fig. 6. Experiment 2. Longitudinal histological representations of tibiae stabilised with (a-c) the unmodified control K-wire, (d-f) SBMA K-wire and (g-i) SBMA + CHX K-wire. (a,d,g) Gross histological view showed the presence of new bone callus (nb) around the osteotomy, even though the SBMA and SBMA + CHX groups indicated misalignment of the proximal and distal portions of the tibia. (b,e,h) All groups showed the presence of trabeculae (arrow), osteoblasts (\#) and spindle cells $\left(^{*}\right)$. (h) Chondrocytes (arrowhead) around the osteotomy indicated endochondral bone formation in the SBMA + CHX group. The tissues directly in contact with the extracted K-wire of (c) the unmodified control and (f) SBMA groups indicated normal host response, with the presence of chondrocytes (arrowhead) and spindle cells $\left({ }^{*}\right)$. The SBMA + CHX bone tissue indicated an inflammatory response to the implant, with the presence of dark purple neutrophils and remnants of haematoma (pink) (stained with haematoxylin and eosin). Images captured at (a,d,g) 2.5×, $(\mathbf{b}, \mathbf{e}, \mathbf{h}) \mathbf{1 0 \times}$ and $(\mathbf{c}, \mathbf{f}, \mathbf{i}) 20 \times$ magnification. 
$\mathbf{a}$

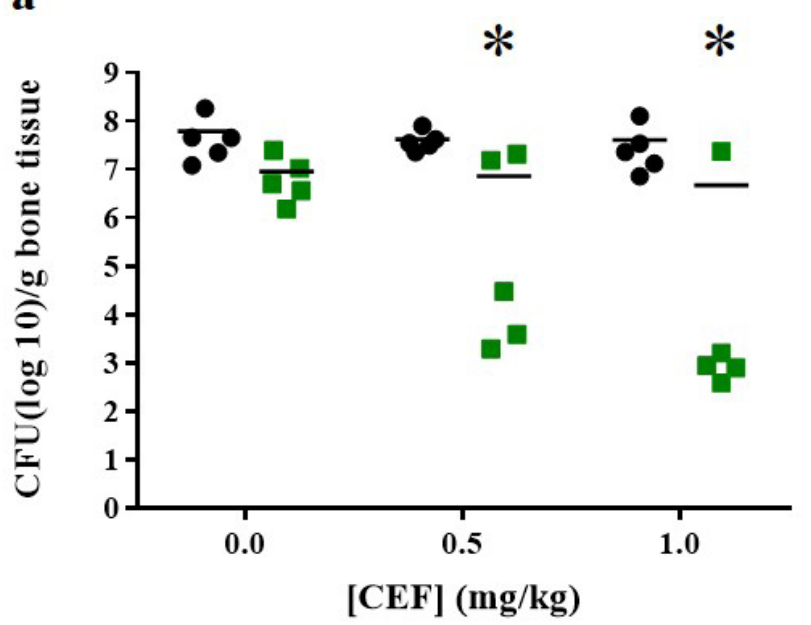

b $\bullet$ Unmodified $\square$ SBMA + CHX

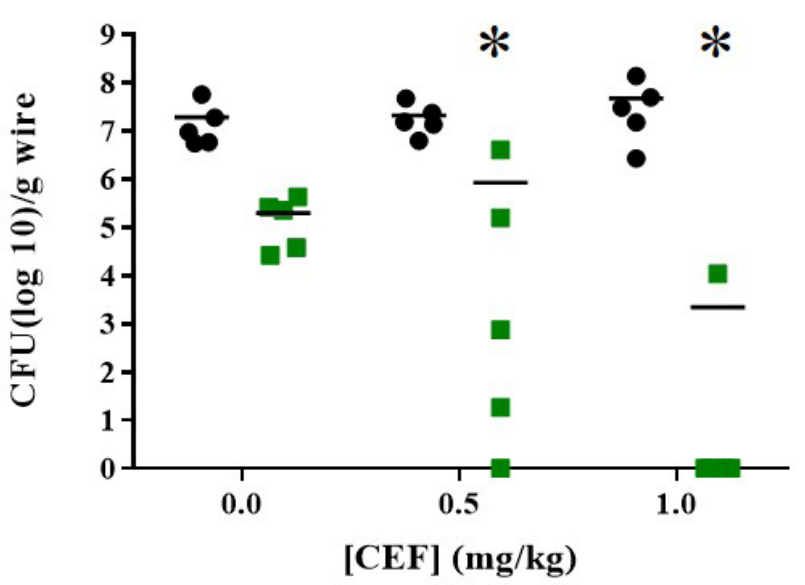

Fig. 7. Experiment 3. Effect of the SBMA + CHX modification when combined with systemic cefazolin (CEF) (subcutaneous, twice daily for $72 \mathrm{~h}$ ) within (a) bone and (b) on the K-wire surface. By adding 0.5 or $1.0 \mathrm{mg} / \mathrm{kg}$ cefazolin, the anti-infective efficacy of the modification improved and resulted significantly different ( $p<0.05$, two-way ANOVA, Bonferroni post-hoc test) than the unmodified control K-wire within the same cefazolin concentration.
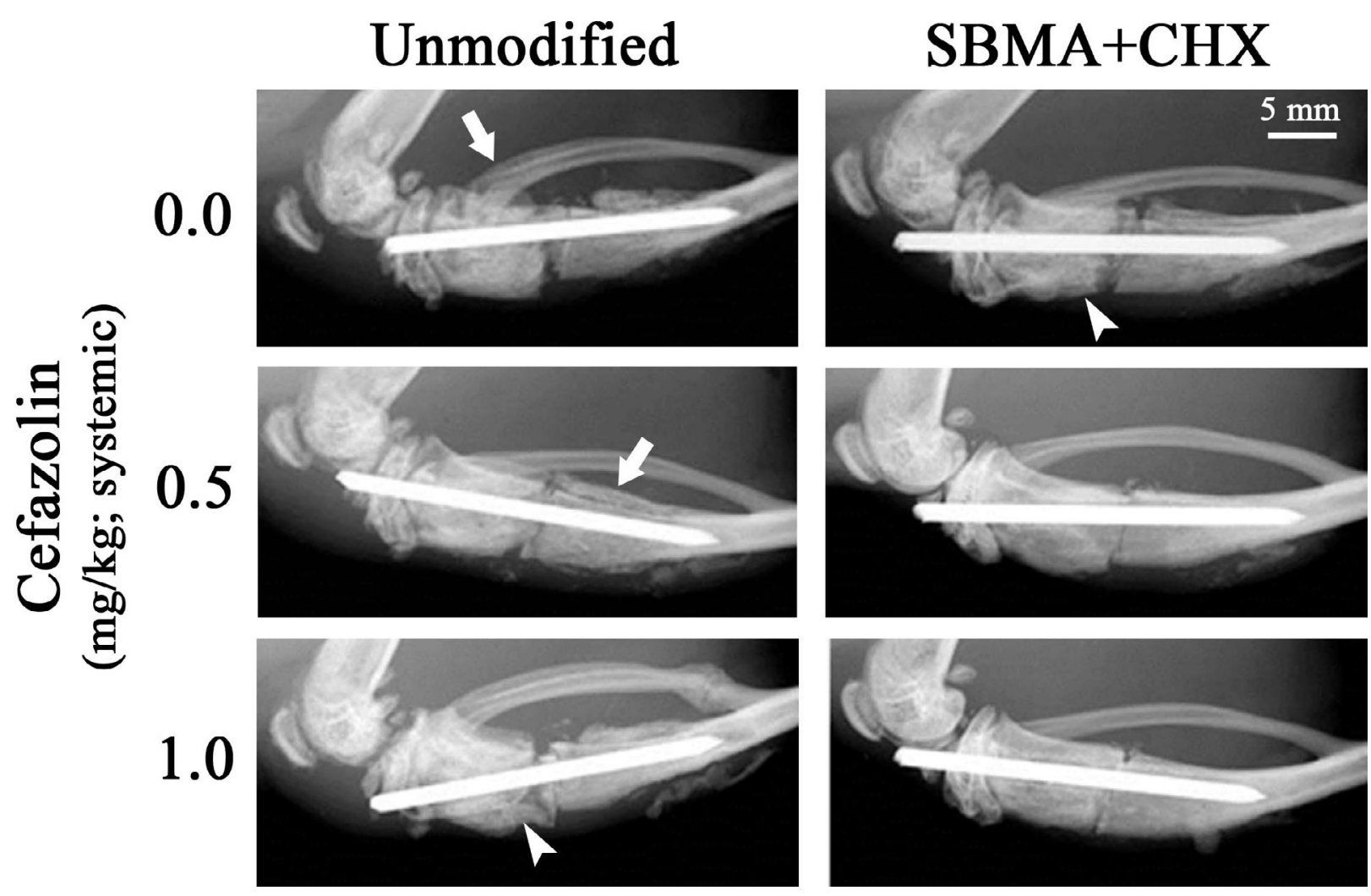

Fig. 8. Experiment 3. Representative radiographs 2 weeks post-operative demonstrating the morphological difference between the unmodified control K-wire and the SBMA + CHX modified K-wire when combined with cefazolin. Even when treated with systemic cefazolin for $72 \mathrm{~h}$, bones that received the unmodified control wire showed signs of periosteal reaction (arrowhead) and osteolysis of the tibia (arrow). There were also small fractures located around the osteotomy. When an implant with the SBMA + CHX coating was placed within the bone and supplemented with systemic cefazolin, there was an improvement of bone quality and signs of union. 
Table 3. Findings for experiment 4. Radiographic osteolysis as indicated by the presence of bone remodelling, cortical thinning and increased lucency. Bone union as indicated by lack of integrity when placed on span for mechanical testing. $p<0.05$ Fisher's $2 \times 2$ contingency table for yes/no regarding radiographic osteolysis or presence of bone union at mechanical testing.

\begin{tabular}{|l|c|c|c|}
\hline & Unmodified $(n=9)$ & SBMA + CHX $(n=9)$ & $p$-value \\
\hline Radiographic osteolysis & 7 & 4 & 0.092 \\
\hline Bone union & 1 & 7 & $<0.05$ \\
\hline
\end{tabular}

bone resorption in the form of a thin cortical bone and increased lucency extending the length of the shaft. As measured by histological scoring, although yielding no significant differences, the callus of the unmodified group contained a larger number of spindle and inflammatory cells, namely neutrophils, compared to the SBMA + CHX K-wire (Table 4). In addition, bacteria were present throughout the medullary canal, the cortical bone and the fracture callus in the unmodified K-wire. When the SBMA $+\mathrm{CHX}$ wire was used, the number of bacteria on the bone surface decreased, leaving bacterial traces within the lacunae, revealing a tissue diffusion limitation of the CHX (Table 4). Inflammatory cells, empty lacunae and bacteria-filled lacunae within the unmodified control group provided evidence of infection (Fig. 11a-c). The SBMA + CHX group showed signs of new bone formation and the absence of bacteria within the fracture callus (Fig. 11d-f). 4 animals were euthanised and excluded, 3 unmodified control due to sequestration of the K-wire leading to destabilisation of the operative tibia and 1 SBMA $+\mathrm{CHX}$ due to the K-wire rupturing through the posterior cortex of the tibia.

\section{Discussion}

Despite meticulous wound care, IM-nail-associated infections remain a leading complication during fracture fixation (Schmidmaier et al., 2006). The feasibility of a titanium implant, modified with a novel non-fouling CHX-loaded polybetaine coating to reduce the onset of infection without interfering with the natural bone healing process, was investigated. The surface modification of the titanium implant with the CHX-loaded polybetaine coating significantly reduced the onset of infection, but sacrificed the rate of bone union in a sterile environment. When $\mathrm{CHX}$ was not incorporated into the surface modification, large quantities of SBMA were recovered from the contaminated wound. The inclusion of CHX into the titanium surface modification reduced the overall bacterial bioburden within an intact bone by approximately $3 \log$. More impressive, after 2 weeks in vivo, bacteria did not colonise the surface of the CHX-modified titanium implant, despite being present within the bone. This finding provided evidence of the continual presence of CHX on the implant surface. However, when challenged with a fracture, the CHX coating showed decreased antimicrobial effectiveness as compared to an intact tibia. CHX had a relatively short dispersal pattern, unable to reach the outer cortex of the bone and surrounding musculature, as supported by the bacterial colonisation pattern identified in the histological sections. To aid in the antimicrobial function of the coating and increase relevancy to clinical practice, the animals received low doses of systemic cefazolin, a broad-spectrum antibiotic, which, when combined with the CHX coating, reduced the bacterial bioburden. When evaluated in a contaminated fracture model, the combination of systemic cefazolin and CHX-modified implant exhibited a higher union rate and a lower occurrence of osteolysis as compared to an unmodified titanium implant with systemic cefazolin.

Definitive fixations using IM nails are standard practice for civilian trauma fracture fixation and are associated with quicker healing and lower rates of malunion (Hofmann et al., 2015). Internal fixation also has generally positive reviews from patients, due to quick recovery and weight-bearing and little impact on daily activity. Due to the injury size, tissue damage and vasculature disruption of a grade IIIc tibial fracture, infection rates are high with immediate IM nail placement; therefore, definitive coverage and fixation is often delayed until tissues are stable (Lack et al., 2015). Bone infections can decrease union rate, increase hospital time or result in replacement of the implant or amputation of the infected extremity. Lacap and Frisch (Web Ref. 1) report a $14.3 \%$ infection rate when IM nails are used in wartime tibial fractures, requiring removal of the IM nail in 4 out of 5 cases. Although precautions are taken to minimise implant-related infections, complete eradication of a fracture fixation-associated infection is generally not the primary concern. Attentions is focused on fracture consolidation and minimisation of chronic osteomyelitis, with planned implant removal following fracture healing (Zimmerli, 2014; Metsemakers et al., 2016). Although the SBMA+ CHX did not cause a complete eradication of bacteria when used alone in the fracture model, it did reduce the infection toward the established $10^{5}$ organism cut-off for determining clinical wound infection (Rhoads et al., 2008; Black and Costerton, 2010). 
$\mathbf{a}$

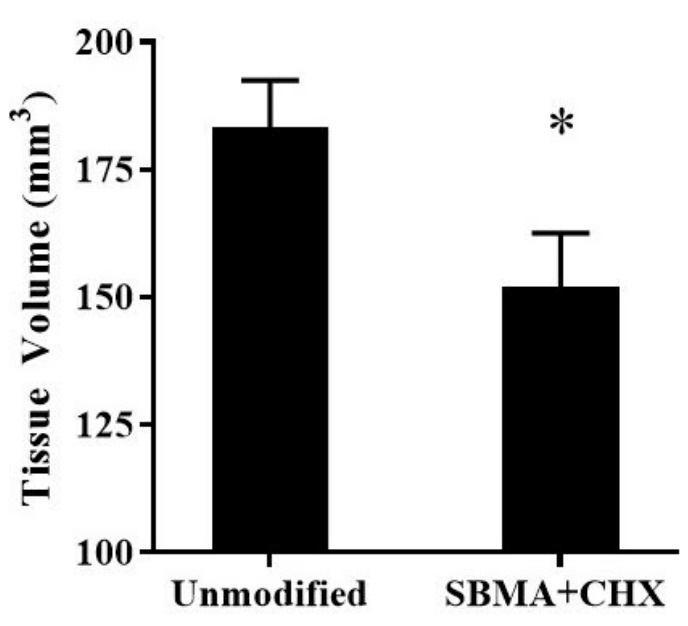

c b

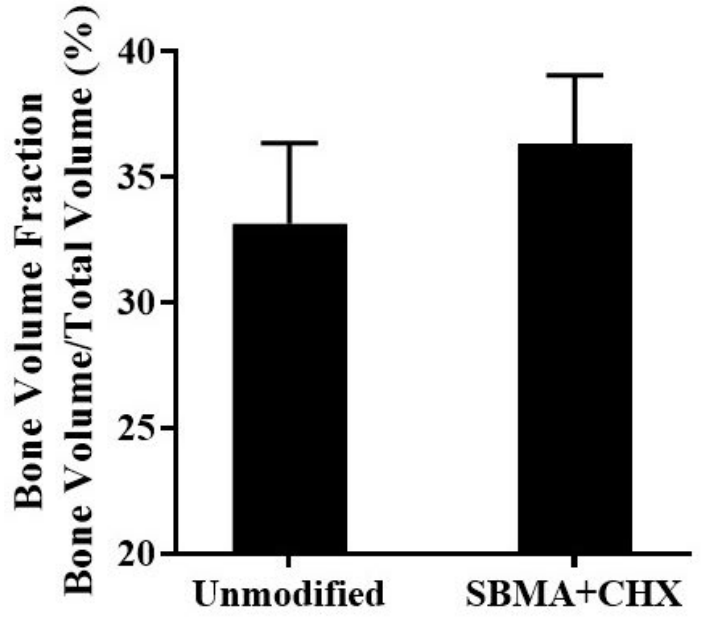

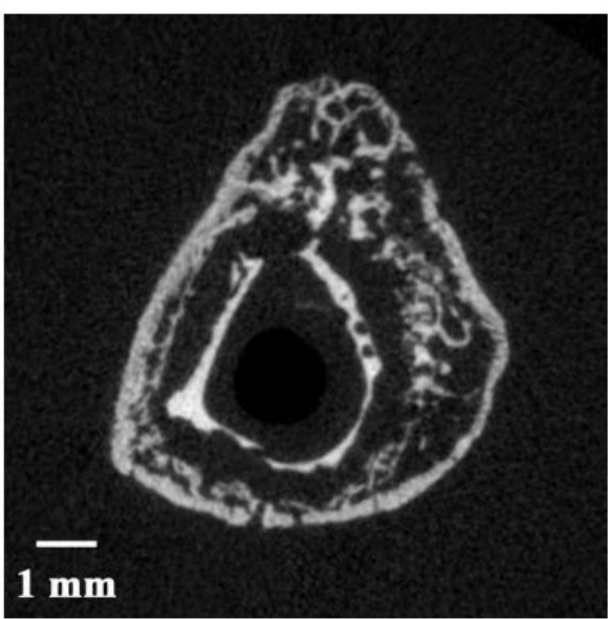

Unmodified

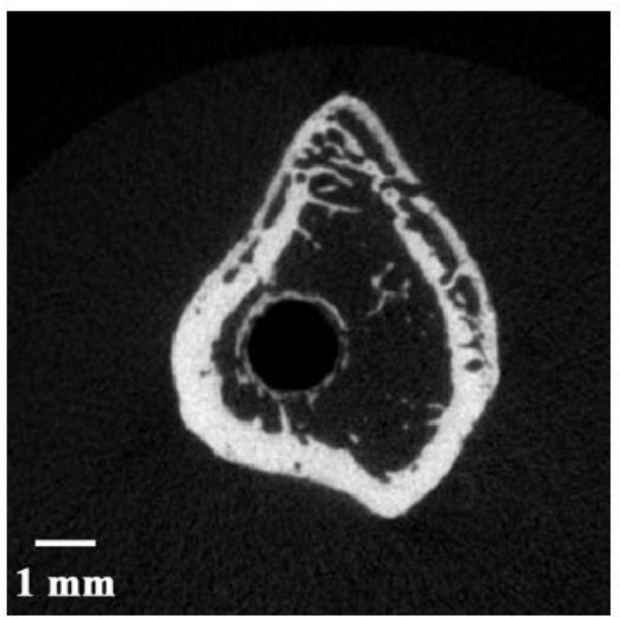

SBMA+CHX

Fig. 9. Experiment 4. $\mu \mathrm{CT}$ morphological analysis of the tibiae recovered from the unmodified control and the SBMA + CHX groups. (a) A significant difference in tissue volume $\left(\mathrm{mm}^{3}\right)$ between the two groups $\left({ }^{*} p<0.05\right)$ was measured. (b) A slight but insignificant decrease in bone volume fraction of the unmodified group compared to the SBMA + CHX group $(p=0.46)$ was detected. (c) Representative cross-sectional $\mu \mathrm{CT}$ images displaying the gross differences in tibiae acquired within $200 \mu \mathrm{m}$ of the osteotomy. The unmodified group displayed areas of cortical thinning, whereas the SBMA + CHX group presented minimal cortical resorption, bony callus and bone deposition around the wire.

Extensive research has focused on surface modifications to decrease the incidence of infection due to implanted materials (Campoccia et al., 2013). Multiple approaches are identified to deter bacterial attachment, prevent biofilm formation or eradicate local bacteria prior to attachment (Darouiche et al., 1999; Cheng et al., 2007; Sanchez et al., 2013; Harmata et al., 2015). Surface modification, such as anti-fouling coatings, can alter the tendency of bacteria to adhere to the implant by reducing protein absorbance, thus moderating cellular interaction (Ruggieri et al., 1987). Anti-fouling zwitterionic SBMA coatings reduce bacteria and biofilm formation on vascular catheters. Smith et al. (2012) identify a poly-SBMA catheter coating that reduces $S$. aureus by $2 \log$ in vitro, but with a slightly decreased anti-fouling response in an ectopic mouse model. Anti-fouling coatings could play an integral part toward reducing device-related orthopaedic infections. However, as discovered in the current study, the use of the SBMA coating alone was ineffective at reducing the infection onset in vivo. Further investigation regarding an antifouling coating that does not include an adjunctive antimicrobial is necessary to completely understand its utility in an orthopaedic setting.

Reservoir coatings that contain antimicrobial agents are more commonly investigated for orthopaedic applications (Campoccia et al., 2013). The only coated orthopaedic implants available for clinical use is a gentamicin-coated IM nail, approved 
for use only in Europe (Metsemakers et al., 2015). Lucke et al. designed the gentamicin coating to have an initial burst release, resulting in high levels at the tissue/implant interface, with a nearly complete eradication of $S$. aureus in a rat K-wire model (Lucke et al., 2003; Schmidmaier et al., 2006). In clinical testing, the use of the gentamicin-coated nail reduces the incidence of infection in small single centre cohorts (Metsemakers et al., 2015). To more accurately determine its usefulness in decreasing the incidence of infection, a large randomised clinical trial needs to be performed.

While surface coatings may prevent bacterial colonisation and infection, it is crucial to consider the effect of the surface modification on the host tissue. SBMA surface coatings evade host tissue interaction by resisting protein and bacterial absorption, thus increasing the device longevity (Chang et al., 2008; Smith et al., 2012). However, although protein absorption is discouraged, mineralisation of the SBMA surface is encouraged. In vitro, compared to an unmodified titanium substrate, calcium apatite surface coverage improves by $40 \%$ when a SBMA-modified titanium substrate is used (Liu et al., 2014). By improving the interaction between bone mineralisation and implant surface, SBMA modifications may improve integration of the implant, reducing bacterial attachment susceptibility (Gristina et al., 1988).

The amplified use of antibiotics has increased the incidence of antibiotic-resistant bacteria, prompting investigation toward alternate bactericidal materials. $\mathrm{CHX}$ is currently used in surgical preparation, as an oral and wound irrigant (Mohammadi and Abbott, 2009; Barnes et al., 2014; Zhang et al., 2017), and in preliminary investigation toward orthopaedic implant modification (Darouiche et al., 1998; Riool et al., 2017). At high concentrations, CHX causes complete loss of membrane integrity, resulting in cell lysis and death (Hugo and Longworth 1964; Williamson et al., 2017). At lower concentration, $\mathrm{CHX}$ is bacteriostatic, binding to the bacterial cell membrane and inhibiting cellular respiration, whereas bacterial removal is aided by the host's natural defences. As a cell wall disruptor, it is a broadspectrum antiseptic and, if used appropriately and correctly, it leaves little chance of bacteria acquiring resistance (Hasanvand et al., 2015; Kampf, 2016). Considering that the MIC for UAMS-1 and for other methicillin-susceptible and methicillin-resistant $S$. aureus strains is $2 \mu \mathrm{g} / \mathrm{mL}$, implant coatings do not require a large quantity of $\mathrm{CHX}$ (Kampf, 2016).
Plain Radiograph
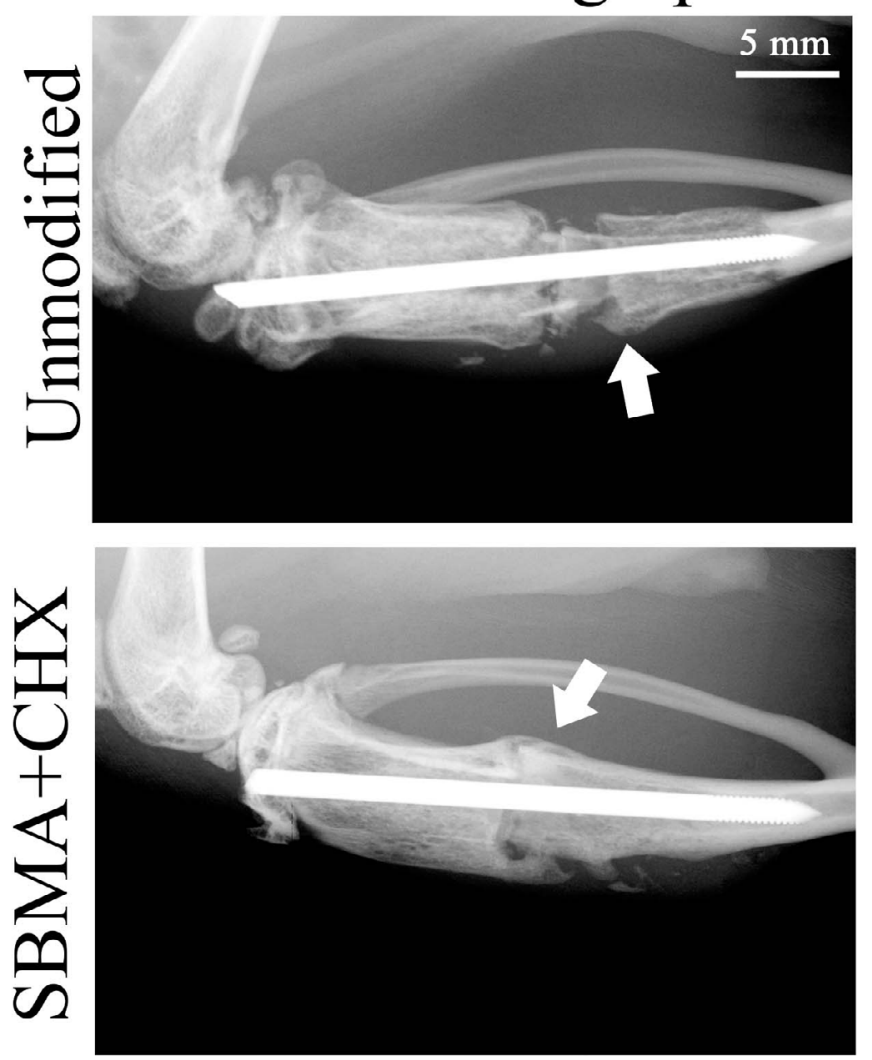

$\mu \mathrm{CT}$
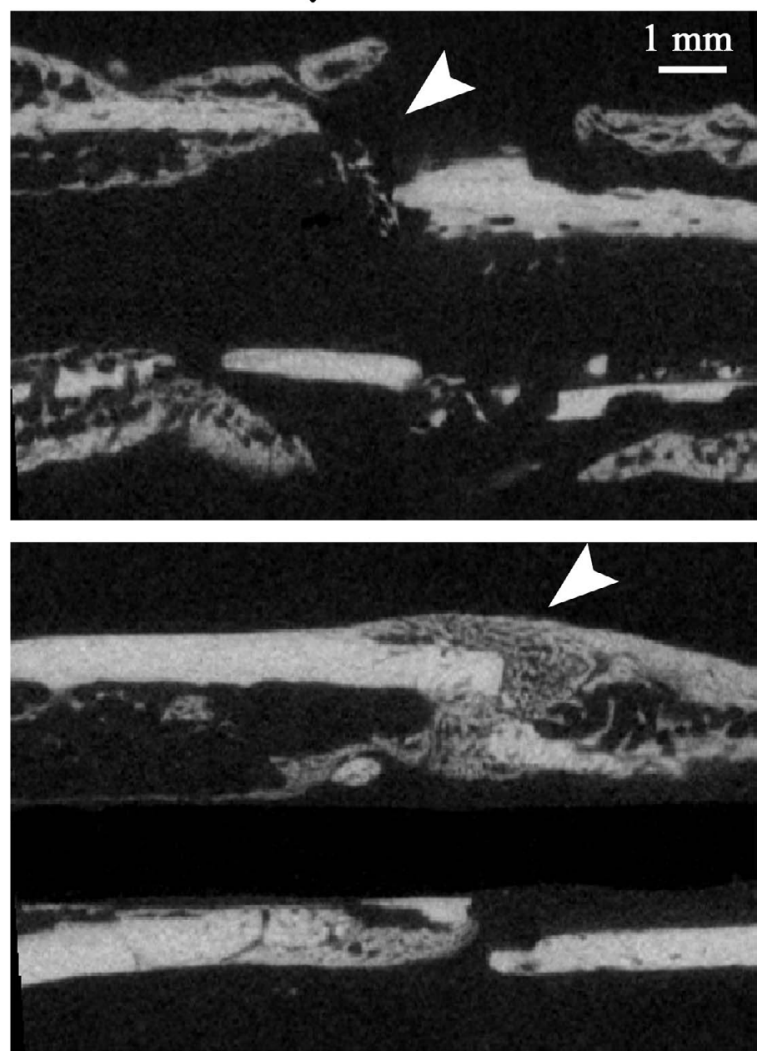

Fig. 10. Experiment 4. Radiographic representation 4 weeks post-operative of the morphological differences between inoculated tibiae implanted with an unmodified control K-wire and a SBMA + CHX-modified K-wire. The tibia with unmodified control K-wires exhibited signs of periosteal reaction and osteolysis (arrow) and non-union (arrowhead). Tibiae stabilised with SBMA + CHX-modified wires showed signs of callus formation (arrow) and union (arrowhead). 
Table 4. Histological scoring for experiment 4. Bacterial presence, represented as number of samples with identified bacteria per total samples analysed.

\begin{tabular}{|c|c|c|c|c|c|}
\hline \multicolumn{6}{|l|}{ Tissue scoring } \\
\hline \multicolumn{6}{|l|}{ Callus quality } \\
\hline \multicolumn{3}{|l|}{ Unmodified } & \multicolumn{3}{|l|}{ SBMA + CHX } \\
\hline \multicolumn{3}{|c|}{$3.8 \pm 0.45$} & \multicolumn{3}{|l|}{$2.71 \pm 1.25$} \\
\hline \multicolumn{6}{|c|}{ Bacteriological scoring } \\
\hline \multicolumn{6}{|c|}{ Bacteria Presence } \\
\hline \multicolumn{3}{|l|}{ Unmodified } & \multicolumn{3}{|l|}{ SBMA + CHX } \\
\hline Medullary canal & Cortical bone & Fracture callus & Medullary canal & Cortical bone & Fracture callus \\
\hline $4 / 5$ & $4 / 5$ & $4 / 5$ & $1 / 7$ & $2 / 7$ & $4 / 7$ \\
\hline \multicolumn{6}{|l|}{ Bacteria location } \\
\hline \multicolumn{3}{|l|}{ Unmodified } & \multicolumn{3}{|l|}{$\mathrm{SBMA}+\mathrm{CHX}$} \\
\hline \multicolumn{3}{|l|}{$3 \pm 0$} & \multicolumn{3}{|l|}{$2.3 \pm 1$} \\
\hline
\end{tabular}

Wang et al. (2014) have developed a CHX releasing non-fouling SBMA coating that anneals to the surface of titanium, preventing abrasive stripping during implant placement. While the daily release rate measured in the current study was lower than the MIC, the introduction of the released CHX, in conjunction with cefazolin and the host defences, reduced the infection rate within the rat tibiae. In vitro, the leaching $\mathrm{CHX}$ reduced $S$. aureus attachment by $3 \log$ as compared to unmodified titanium. The bone condition contributed to the antimicrobial effect of the $\mathrm{CHX}$ surface coating. When placed within an intact bone, such as when placing a prosthetic hip stem, a significant reduction in bioburden was recorded in the bone tissue. However, when placed in a contaminated fracture model, the treatment effect of the CHX coating was reduced. This was potentially related to the increased bleeding around the osteotomy, diluting the released $\mathrm{CHX}$, and the tissue diffusion limitation of the CHX. Despite the inception of CHX coatings for infection reduction, little is understood about its use for orthopaedic applications and its potential effect on bone healing (Riool et al., 2017). CHX digluconate is cytotoxic at high concentration delivered for short intervals; however, the longer osteoblasts are exposed to even low concentrations of $\mathrm{CHX}$, the larger is the decrease in viability (Giannelli et al., 2008). The current study determined that coating and subsequent release of $\mathrm{CHX}$ had direct effects on bone healing.

This study had several limitations. First, only a single pathogen was investigated, but $S$. aureus is the most common pathogen of orthopaedic infection (Zimmerli and Sendi, 2017). Second, the mode of bacterial inoculation, directly into the wound at the time of implant placement mimicked what would normally be seen in surgical site infections. Although, in large Gustilo Anderson IIIc fractures, which traditionally follow an "outside-in" injury pattern and are highly contaminated with foreign material prior to definitive IM nail placement, it is postulated that the introduction of $S$. aureus occurs during hospitalisation and not at the time of injury (Burns et al., 2012). Also, this model did not provide ultra-rigid fixation of the tibia, which would have led to bone healing through a primary intramembranous mechanism. Instead, this non-locking IM nail model, similar to Miclau et al. (2007), provided partial stabilisation and initiated secondary endochondral bone formation, the most common mechanism of fracture healing. Finally, data from quantitative histomorphometry, which would have provided additional information regarding the callus formation, were lacking. However, $\mu \mathrm{CT}$ provided values for mineralised bone tissue that were supported by histology.

Reduction of bacterial attachment is necessary for successful orthopaedic implant placement. Implant infection could be catastrophic, requiring extensive antibiotics and subsequent surgical procedures resulting in delayed healing. Surface modification has proven useful in Europe, with the product yet to migrate to the United States. Although not as prevalent in the civilian sector, implant-related infection remains a leading complication in the combat wounded. It is anticipated that the treatment time will increase in upcoming conflicts, thereby further increasing complications, such as infection. An inexpensive implant that will thwart bacterial colonisation of the fracture, while not increasing the burden on the surgeon or patient, is an obvious path toward preparing the wound for its best chances to heal timely and appropriately.

\section{Conclusion}

IM nails are one of the fixation devices most used by orthopaedic surgeons, but frequently become contaminated with bacteria, thus delaying fracture union. By applying a non-fouling CHX-releasing coating, the bioburden within the surgical site was reduced. Further investigation is required to optimise $\mathrm{CHX}$ use and better estimate the effect of the coating on long-term bone healing and bioburden reduction. 

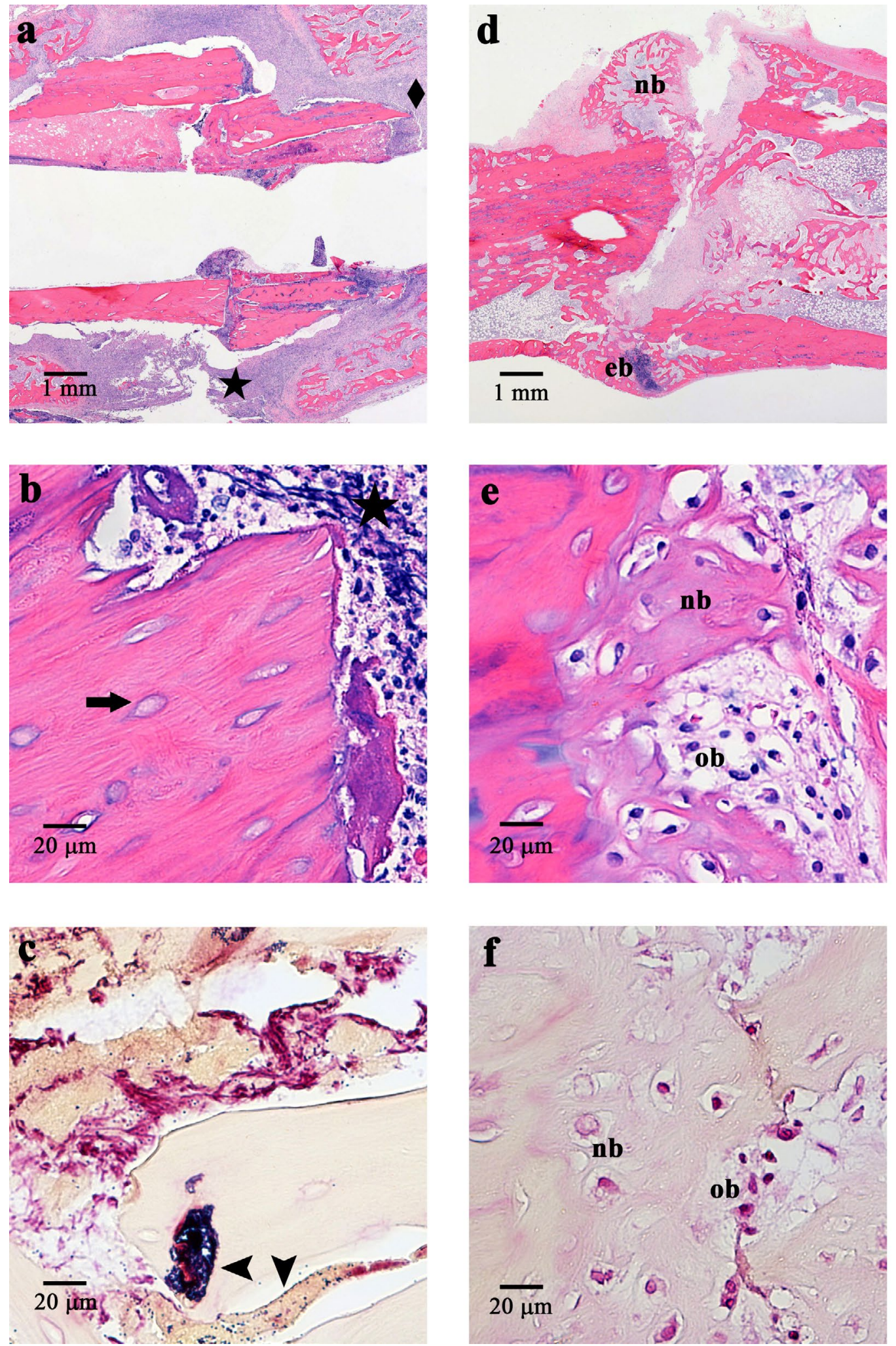

Fig. 11. Experiment 4. Histological representation of the S. aureus-inoculated tibiae stabilised with either (a-c) an unmodified control K-wire or (d-f) a SBMA + CHX-modified K-wire. (a) A longitudinal view of the tibia with the presence of inflammatory cells (star) around an osteotomy fixed with an unmodified control K-wire and bone resorption marked by the absence of cortical bone (diamond). (b) Neutrophils (star) surrounding a piece of necrotic bone, identified by the empty lacunae (arrow). (c) Deep violet gram-positive $S$. aureus within and along a piece of necrotic bone (arrow head). (d) A longitudinal section of the tibia fixed with SBMA + CHX-modified K-wire showing the presence of new bone callus $(\mathrm{nb})$ and endochondral bone formation (eb). (e) New bone (nb) formation with callus and osteoblasts (ob) within it. (f) Absence of identifiable S. aureus within the new bone (nb) and osteoblasts (ob). Stained with haematoxylin and eosin or a modified gram stain. Images acquired at (a,d) $2.5 \times$ and $(\mathbf{b}, \mathbf{c}, \mathbf{e}, \mathbf{f}) 40 \times$ magnification. 


\section{Acknowledgements}

This work was supported by W81XWH-15-0114. SMS is a member of the Oak Ridge Institute of Science and Education. The authors would like to thank the members of the Wenke Bone group at the US Army Institute of Surgical Research for their hard work and dedication to the project.

\section{Disclaimer}

The opinions or assertions contained herein are the private views of the author and are not to be construed as official or as reflecting the views of the Department of the Army or the Department of Defence.

\section{References}

Barnes S, Spencer M, Graham D, Johnson HB (2014) Surgical wound irrigation: a call for evidencebased standardization of practice. Am J Infect Control 42: 525-529.

Bebko SP, Green DM, Awad SS (2015) Effect of a preoperative decontamination protocol on surgical site infections in patients undergoing elective orthopedic surgery with hardware implantation. JAMA Surg 150: 390-395.

Becerra SC, Roy DC, Sanchez CJ, Christy RJ, Burmeister DM (2016) An optimized staining technique for the detection of Gram positive and Gram negative bacteria within tissue. BMC Res Notes 9: 216.

Belmatoug N, Crémieux A-C, Bleton R, Volk A, Saleh-Mghir A, Grossin M, Garry L, Carbon C (1996) A new model of experimental prosthetic joint infection due to methicillin-resistant Staphylococcus aureus: a microbiologic, histopathologic, and magnetic resonance imaging characterization. J Infect Dis 174: 414-417.

Black CE, Costerton JW (2010) Current concepts regarding the effect of wound microbial ecology and biofilms on wound healing. Surg Clin North Am 90: 1147-1160.

Burns TC, Stinner DJ, Mack AW, Potter BK, Beer R, Eckel TT, Possley DR, Beltran MJ, Hayda RA, Andersen RC, Keeling JJ, Frisch HM, Murray CK, Wenke JC, Ficke JR, Hsu JR (2012) Microbiology and injury characteristics in severe open tibia fractures from combat. J Trauma Acute Care Surg 72: $1062-$ 1067.

Campoccia D, Montanaro L, Arciola CR (2013) A review of the biomaterials technologies for infectionresistant surfaces. Biomaterials 34: 8533-8554.

Chang Y, Liao SC, Higuchi A, Ruaan RC, Chu CW, Chen WY (2008) A highly stable nonbiofouling surface with well-packed grafted zwitterionic polysulfobetaine for plasma protein repulsion. Langmuir 24: 5453-5458.
Cheng G, Zhang Z, Chen S, Bryers JD, Jiang S (2007) Inhibition of bacterial adhesion and biofilm formation on zwitterionic surfaces. Biomaterials 28: 4192-4199.

CLSI (2013) Performance standards for antimicrobial susceptibility testing; twenty-third information supplement M100-S23. Wayne, PA, USA.

Costerton JW, Montanaro L, Arciola CR (2005) Biofilm in implant infections: its production and regulation. Int J Artif Organs 28: 1062-1068.

Darouiche RO, Green G, Mansouri MD (1998) Antimicrobial activity of antiseptic-coated orthopaedic devices. Int J Antimicrob Agents 10: 8386.

Darouiche RO, Raad, II, Heard SO, Thornby JI, Wenker OC, Gabrielli A, Berg J, Khardori N, Hanna H, Hachem R, Harris RL, Mayhall G (1999) A comparison of two antimicrobial-impregnated central venous catheters. Catheter study group. N Engl J Med 340: 1-8.

Fuchs T, Stange R, Schmidmaier G, Raschke MJ (2011) The use of gentamicin-coated nails in the tibia: preliminary results of a prospective study. Arch Orthop Trauma Surg 131: 1419-1425.

Giannelli M, Chellini F, Margheri M, Tonelli P, Tani A (2008) Effect of chlorhexidine digluconate on different cell types: a molecular and ultrastructural investigation. Toxicol In Vitro 22: 308-317.

Gillaspy AF, Hickmon SG, Skinner RA, Thomas JR, Nelson CL, Smeltzer MS (1995) Role of the accessory gene regulator (agr) in pathogenesis of staphylococcal osteomyelitis. Infect Immun 63: 3373-3380.

Gristina AG, Naylor P,Myrvik Q (1988) Infections from biomaterials and implants: a race for the surface. Med Prog Technol 14: 205-224.

Gupta N, You C, Giare-Patel K, Sechrist K (2014) Devices with anti-thrombogenic and anti-microbial treatment. US20160015863A1. US application.

Gustilo RB, Anderson JT (1976) Prevention of infection in the treatment of one thousand and twentyfive open fractures of long bones: retrospective and prospective analyses. J Bone Joint Surg Am 58: 453458.

Gustilo RB, Mendoza RM, Williams DN (1984) Problems in the management of type III (severe) open fractures: a new classification of type III open fractures. J Trauma 24: 742-746.

Harmata AJ, Ma Y, Sanchez CJ, Zienkiewicz KJ, Elefteriou F, Wenke JC, Guelcher SA (2015) D-amino acid inhibits biofilm but not new bone formation in an ovine model. Clin Orthop Relat Res 473: 3951-3961.

Harris AM, Althausen PL, Kellam J, Bosse MJ, Castillo R (2009) Complications following limbthreatening lower extremity trauma. J Orthop Trauma a 23: 1-6.

Hasanvand A, Ghafourian S, Taherikalani M, Jalilian FA, Sadeghifard N, Pakzad I (2015) Antiseptic resistance in methicillin sensitive and methicillin resistant Staphylococcus aureus isolates from some major hospitals, Iran. Recent Pat Antiinfect Drug Discov 10: 105-112. 
Hofmann Z, Dietz SO, Pairon P, Rommens PM (2015) The role of intramedullary nailing in treatment of open fractures. Eur J Trauma Emerg Surg 41: 39-47.

Hugo WB, Longworth AR (1964) Some aspects of the mode of action of chlorhexidine. J Pharm Pharmacol 16: 655-662.

Kampf G (2016) Acquired resistance to chlorhexidine - is it time to establish an 'antiseptic stewardship' initiative?. J Hosp Infect 94: 213-227.

Keeling JJ, Gwinn DE, Tintle SM, Andersen RC, McGuigan FX (2008) Short-term outcomes of severe open wartime tibial fractures treated with ring external fixation. J Bone Joint Surg Am 90: 2643-2651.

Lack WD, Karunakar MA, Angerame MR, Seymour RB, Sims S, Kellam JF, Bosse MJ (2015) Type III open tibia fractures: immediate antibiotic prophylaxis minimizes infection. J Orthop Trauma 29: 1-6.

Lerner A, Fodor L, Soudry M (2006) Is staged external fixation a valuable strategy for war injuries to the limbs?. Clin Orthop Relat Res 448: 217-224.

Lim KS, Kam PC (2008) Chlorhexidinepharmacology and clinical applications. Anaesth Intensive Care 36: 502-512.

Liu P, Domingue E, Ayers DC, Song J (2014) Modification of Ti6Al4V substrates with well-defined zwitterionic polysulfobetaine brushes for improved surface mineralization. ACS Appl Mater Interfaces 6: 7141-7152.

Lucke M, Schmidmaier G, Sadoni S, Wildemann B, Schiller R, Haas NP, Raschke M (2003) Gentamicin coating of metallic implants reduces implant-related osteomyelitis in rats. Bone 32: 521-531.

Lucke M, Wildemann B, Sadoni S, Surke C, Schiller R, Stemberger A, Raschke M, Haas NP, Schmidmaier G (2005) Systemic versus local application of gentamicin in prophylaxis of implant-related osteomyelitis in a rat model. Bone 36: 770-778.

Maki DG, Stolz SM, Wheeler S, Mermel LA (1997) Prevention of central venous catheter-related bloodstream infection by use of an antisepticimpregnated catheter. A randomized, controlled trial. Ann Intern Med 127: 257-266.

McDonnell G, Russell AD (1999) Antiseptics and disinfectants: activity, action, and resistance. Clin Microbiol Rev 12: 147-179.

Metsemakers WJ, Kuehl R, Moriarty TF, Richards RG, Verhofstad MH, Borens O, Kates S, Morgenstern $M$ (2016) Infection after fracture fixation: current surgical and microbiological concepts. Injury 16: 30470-30473.

Metsemakers WJ, Reul M, Nijs S (2015) The use of gentamicin-coated nails in complex open tibia fracture and revision cases: a retrospective analysis of a single centre case series and review of the literature. Injury 46: 2433-2437.

Miclau T, Lu C, Thompson Z, Choi P, Puttlitz C, Marcucio R, Helms JA (2007) Effects of delayed stabilization on fracture healing. J Orthop Res 25: 1552-1558.
Mohammadi Z, Abbott PV (2009) The properties and applications of chlorhexidine in endodontics. Int Endod J 42: 288-302.

O'Toole RV, Gary JL, Reider L, Bosse MJ, Gordon WT, Hutson J, Quinnan SM, Castillo RC, Scharfstein DO, MacKenzie EJ (2017) A prospective randomized trial to assess fixation strategies for severe open tibia fractures: modern ring external fixators versus internal fixation (FIXIT Study). J Orthop Trauma 31 Suppl 1: S10-S17.

Patzakis MJ, Wilkins J (1989) Factors influencing infection rate in open fracture wounds. Clin Orthop Relat Res 243: 36-40.

Pucher JJ, Daniel JC (1992) The effects of chlorhexidine digluconate on human fibroblasts in vitro. J Periodontol 63: 526-532.

Rhoads DD, Wolcott RD, Percival SL (2008) Biofilms in wounds: management strategies. J Wound Care 17: 502-508.

Riool M, Dirks AJ, Jaspers V, de Boer L, Loontjens TJ, van der Loos CM, Florquin S, Apachitei I, Rijk LN, Keul HA, Zaat SA (2017) A chlorhexidine-releasing epoxy-based coating on titanium implants prevents Staphylococcus aureus experimental biomaterialassociated infection. Eur Cell Mater 33: 143-157.

Ruggieri MR, Hanno PM, Levin RM (1987) Reduction of bacterial adherence to catheter surface with heparin. J Urol 138: 423-426.

Sanchez CJ, Jr., Prieto EM, Krueger CA, Zienkiewicz KJ, Romano DR, Ward CL, Akers KS, Guelcher SA, Wenke JC (2013) Effects of local delivery of D-amino acids from biofilm-dispersive scaffolds on infection in contaminated rat segmental defects. Biomaterials 34: 7533-7543.

Schmidmaier G, Lucke M, Wildemann B, Haas NP, Raschke M (2006) Prophylaxis and treatment of implant-related infections by antibiotic-coated implants: a review. Injury 37 Suppl 2: S105-112.

Shiels SM, Bedigrew KM, Wenke JC (2015) Development of a hematogenous implant-related infection in a rat model. BMC Musculoskelet Disord 16: 255.

Sin MC, Sun YM, Chang Y (2014)Zwitterionic-based stainless steel with well-defined polysulfobetaine brushes for general bioadhesive control. ACS Appl Mater Interfaces 6: 861-873.

Smith RS, Zhang Z, Bouchard M, Li J, Lapp HS, Brotske GR, Lucchino DL, Weaver D, Roth LA, Coury A, Biggerstaff J, Sukavaneshvar S, Langer R, Loose C (2012) Vascular catheters with a nonleaching polysulfobetaine surface modification reduce thrombus formation and microbial attachment. Sci Transl Med 4: 153 ra132.

Tennent DJ, Shiels SM, Sanchez CJ, Jr., Niece KL, Akers KS, Stinner DJ, Wenke JC (2016) Time-dependent effectiveness of locally applied vancomycin powder in a contaminated traumatic orthopaedic wound model. J Orthop Trauma 30: 531-537.

Wang H, Schultz K, Elias K, Stachowski M, Loose C (2014) Anti-infection trauma devices with drug 
release and nonfouling surface modification. J Orthop Trauma 28 Suppl 1: S28-31.

Weinstock BA, Guiney LM, Loose C (2012) Rapid, nondestructive estimation of surface polymer layer thickness using attenuated total reflection fourier transform infrared (ATR FT-IR) spectroscopy and synthetic spectra derived from optical principles. Appl Spectrosc 66: 1311-1319.

Williamson DA, Carter GP, Howden BP (2017) Current and emerging topical antibacterials and antiseptics: agents, action, and resistance patterns. Clin Microbiol Rev 30: 827-860.

Zhang D, Wang XC, Yang ZX, Gan JX, Pan JB, Yin LN (2017) Preoperative chlorhexidine versus povidone-iodine antisepsis for preventing surgical site infection: a meta-analysis and trial sequential analysis of randomized controlled trials. Int J Surg 44: 176-184.

Zimmerli W (2014) Clinical presentation and treatment of orthopaedic implant-associated infection. J Intern Med 276: 111-119.

Zimmerli W, Sendi P (2017) Orthopaedic biofilm infections. APMIS 125: 353-364.

\section{Web References}

1.http://ota.org/media/am/ota07/otapo/OTP07044. htm [16-03-2018]

\section{Discussion with Reviewer}

David Grainger: How likely and affordable is the randomised clinical trial the authors propose for proving the efficacy of a coated tibial nail releasing antibiotics and obtaining regulatory approval?

Authors: No clinical trial is ever affordable on the front end. Rather, costs are incurred during the trial and translated into the cost of the device during distribution. The study would involve a large cohort, considering not only the use of an intramedullary nail, which would be evaluated for its innate ability to stabilise fractures, but also the utility of the implant to ward off potential catastrophic infection. Considering the current infection rate within civilian clinics, it is estimated that over 1200 patients would be required to confidently determine the anti-infective usefulness of the antimicrobial coating. Such a study would be extremely costly. However, the overall impact that orthopaedic device infection and subsequent treatment and surgeries have on healthcare costs must be considered. If healthcare costs can be diminished after years of use, then the funds necessary for a randomised control trial are minor.

David Grainger: Since polymer brush formation quality and reproducibility is highly dependent on the substrate material being grafted (among many other variables), what was the actual experimental evidence that the substrate used yielded SBMA brushes as claimed, instead of many other possible coating architectures using SBMA monomer grafting? Authors: Based on a study with attenuated total reflectance Fourier transform infrared spectroscopy (ATR-FTIR), scanning electron miscroscopy and water content, the surface modification of polyurethane results in a brush-like surface (Smith et al., 2012). Monomers can be grafted on different substrate using different chemistries. For example, modifications on gold (Zhang et al., 2006a) and on glass (Zhang et al., 2006b) through atom-transfer free radial polymerisation are able to graft a more "ideal", very thin brush-like structure (usually $<100 \mathrm{~nm}$ ). In this study, the coating thinness was $>500 \mathrm{~nm}$. This modification might provide more crosslinkings within the bushes and substrates, making it more mechanically and chemically stable for orthopaedic devices.

\section{Additional References}

Zhang Z, Chen S, Chang Y, Jiang S (2006a) Surface grafted sulfobetaine polymers via atom transfer radical polymerization as superflow fouling coatings. J Phys Chem B 110: 10799-10804.

Zhang Z, Chao T, Chen S, Jiang S (2006b) Superflow fouling sulfobetaine and carboxybetaine polymers on glass slide. Langmuir 22: 10072-10077.

Editor's note: The Scientific Editor responsible for this paper was Fintan Moriarty. 